\title{
A CRITICAL DISCOURSE ANALYSIS OF THE ONTARIO GOVERNMENT'S DISSEMINATION OF THE FDK PROGRAM
}

by

Alexandra Willetts, 2015

Honours Bachelor of Social Sciences, University of Ottawa, Ottawa, 2009

Master of Science, The London School of Economics and Political Science, London, 2010

A Major Research Paper

Presented to Ryerson University

In partial fulfillment of the requirements for the degree of

Master of Arts

In the Program of Early Childhood Studies

Toronto, Ontario, Canada, 2015

(C) Alexandra Willetts, 2015 


\section{Author's Declaration}

I hereby declare that I am the sole author of this MRP. This is a true copy of the MRP, including any required final revisions.

I authorize Ryerson University to lend this MRP to other institutions or individuals for the purpose of scholarly research.

I further authorize Ryerson University to reproduce this MRP by photocopying or by other means, in total or in part, at the request of other institutions or individuals for the purpose of scholarly research.

I understand that my MRP may be made electronically available to the public. 


\title{
ABSTRACT \\ ACRITICAL DISCOURSE ANALYSIS OF THE ONTARIO GOVERNMENT'S DISSEMINATION OF THE FDK PROGRAM
}

Master of Arts, 2015

\author{
Alexandra Willetts \\ Program of Early Childhood Studies \\ Ryerson University
}

This major research paper applies a critical discourse analysis (CDA) to examine the Ontario government's rationalization of full day kindergarten to the public and the underlying discursive representation of social citizenship that the government sets forth. A content analysis of nineteen textual documents identified twelve rationales for FDK. A social investment discourse was identified as the dominant discourse underlying these rationales, while a social justice discourse and a combination of both discourses was also present. A CDA of three textual documents indicated that the Ontario government employed nominalization, modality and interdiscursivity to perpetuate the social investment discursive representation of FDK. The prevalence of social investment discourse in the Ontario government's rationalization of FDK holds important implications for advancing just and caring early childhood policy for all children and families.

Keywords: discourse, early childhood, full day kindergarten, Ontario government, social investment, social justice, rationale 


\section{Acknowledgements}

I would like to thank my supervisor, Dr. Rachel Langford. Thank you for your guidance over the course of the past year and for the time and support you provided during the completion of this paper. The opportunity to learn from your expertise has been rewarding and inspiring. Your enthusiasm and feedback have been essential to completing this paper.

Thank you to my second reader, Dr. Kathryn Underwood. I am so grateful to have the opportunity to receive your incredibly valuable feedback and insight regarding my paper. Thank you for your continued support.

I would like to express my gratitude to Natalya Androsova for your support and insight throughout the writing process. The writing sessions that you led were incredibly valuable and I greatly appreciate the time you took to review my paper and the helpful feedback that you provided. I would also like to thank my peers who participated in these sessions and completed an MRP. I am grateful for the opportunity to receive your advice, to learn about your research and to share in this process with you.

Thank you to all of my peers and professors in the Masters of Early Childhood Studies program. It has been a privilege to learn and study with and from you throughout the course of completing this program.

Thank you to my family and friends for your endless encouragement. This paper would not have been possible without you. 


\section{Dedication}

I would like to dedicate this MRP to my family and to my partner. Your constant care and belief in me means everything. 


\section{Table of Contents}

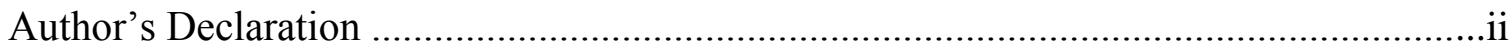

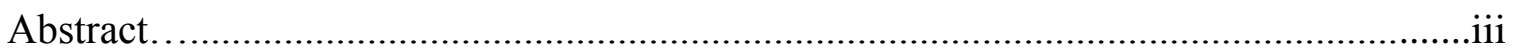

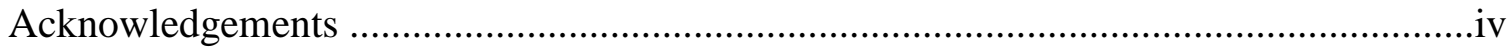

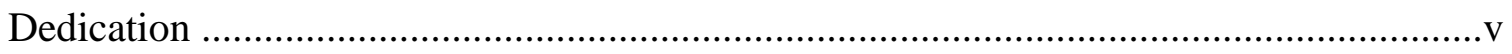

Table of Contents …….........................................................................................

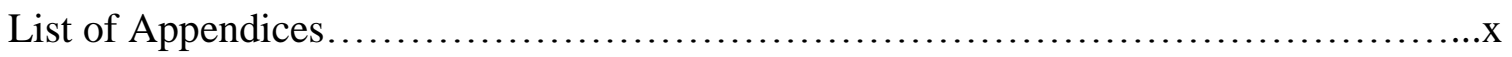

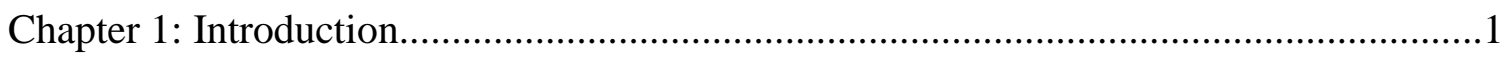

Purpose of the Study ................................................................

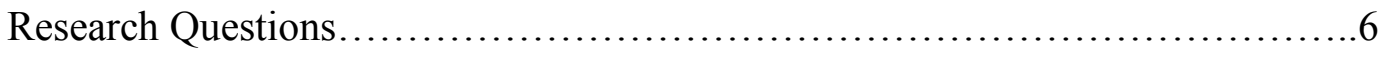

Theoretical Framework.....................................................

Position of the Researcher......................................................11

Chapter 2: Historical Background of FDK...................................................................

Emergence of the FDK Program in Ontario........................................................13

Overview of the FDK Policy Initiative and Program............................................15

Early Outcomes of the FDK Program................................................................17

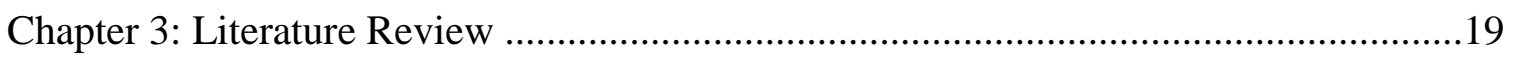

Social investment and Social Rights Models of Citizenship................................19

Social Rights Model of Citizenship.........................................................20

Social Investment Model of Citizenship....................................................20

Debates Regarding Social investment: In Theory and Practice..................23

Political Framing and Discourse..........................................................26

Social Investment Discourse for Early Childhood Policy.....................................27

Supporting Human Capital Development...............................................28 
Supporting Children's Equal Opportunity..........................................31

Supporting Working Parents...........................................................33

Economic Benefits of Early Childhood Programming............................33

Social Justice Discourse for Early Childhood Policy...........................................35

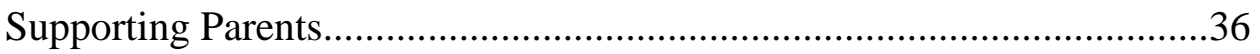

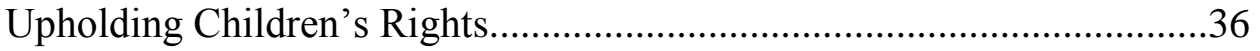

Social Pedagogical Approach to Early Childhood Programming..........37

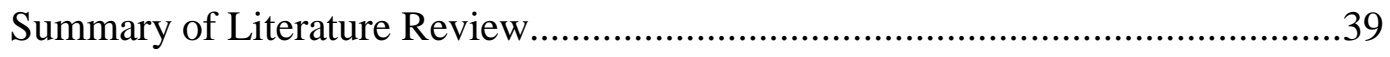

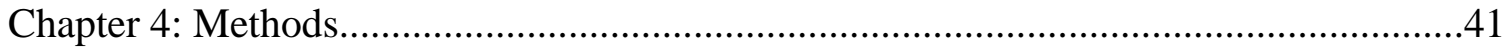

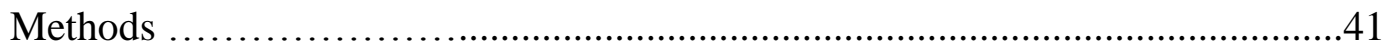

Data Collection for Content Analysis...........................................................42

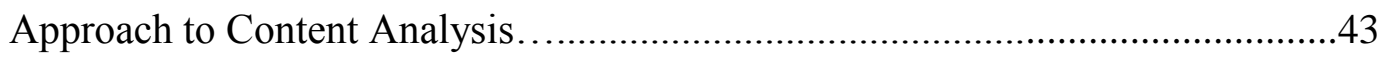

Approach to Enhancing Trustworthiness for CDA...........................................46

Data Collection for CDA...............................................................4

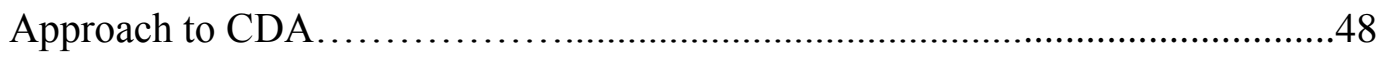

Approach to Enhancing Trustworthiness for Content Analysis...........................51

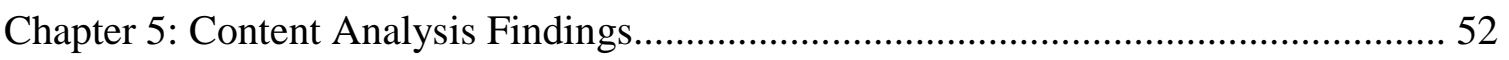

Social Investment-Oriented Rationales....................................................53

Providing Children with the Opportunity for Future Success..................53

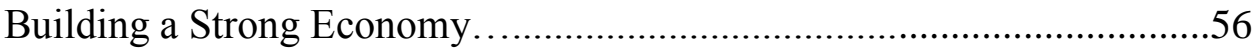

Building a Strong Workforce......................................57

Supporting Working Parents.............................................................59

Supporting Children Experiencing Poverty........................................59

Supporting Future Generations.......................................................6 61

Investing in Children and Educational Programming ...........................61 


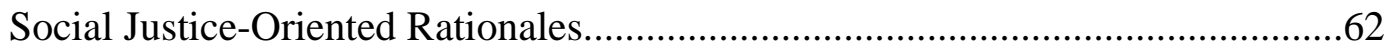

Supporting all Parents/Families.............................................................62

Supporting Children's Present Well-Being............................63

Supporting Children's Holistic Development..............................................64

Social Investment and Social Justice- Oriented Rationales.....................................65

Support for Parents Experiencing Poverty................................................65

Supporting the Public Education System...............................66

Changes in Discursive Representation of FDK According to Genre and Year....67

Summary of Findings: Content Analysis....................................67

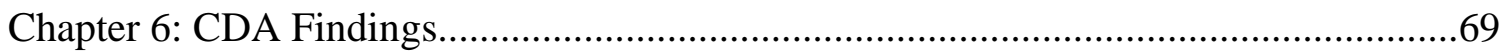

Summary of Texts Included in CDA.....................................69

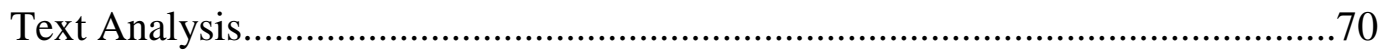

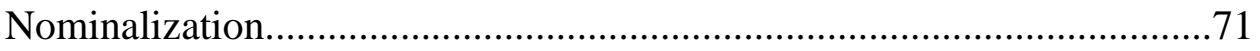

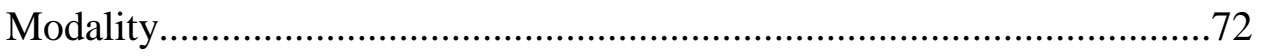

Listing

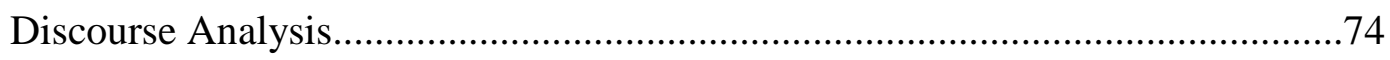

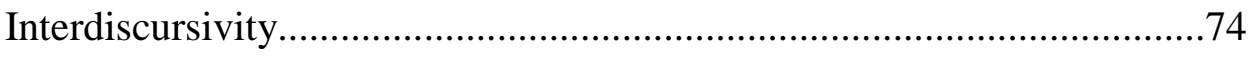

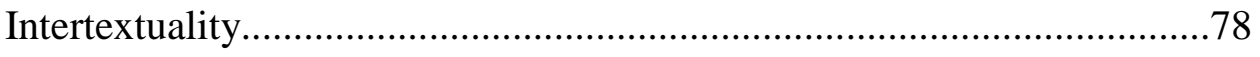

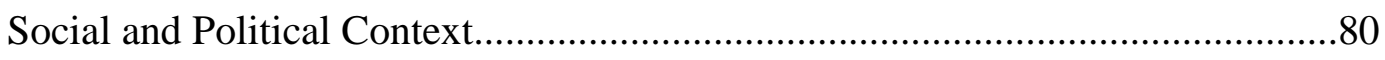

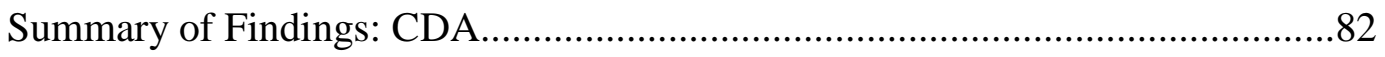

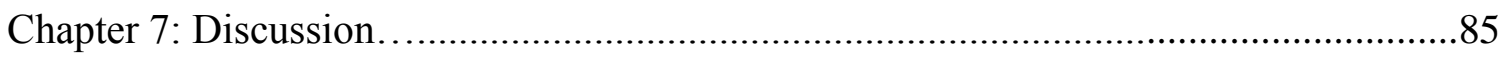

Comparison of Findings to Previous Literature.................................85

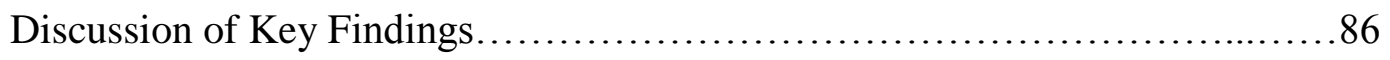

The Limitations of a Human Capital Development Lens..................87 
Emphasis on Supporting Equality and Opportunity..................88

Implications of Employing an Investment Rationale...................90

Benefits of a Social Pedagogical Approach..........................92

Absence of a Children's Rights Frame..............................93

Bridging Social Justice and Social Investment Discourse...............94

Summary of Discussion.............................................95

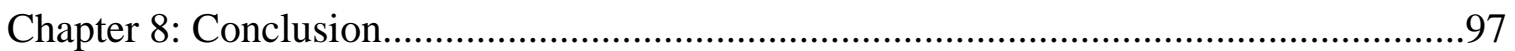

Recommendations for Future Research......................................................98

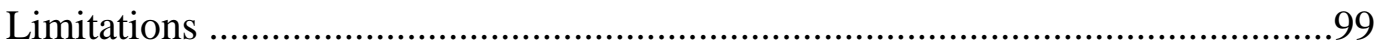

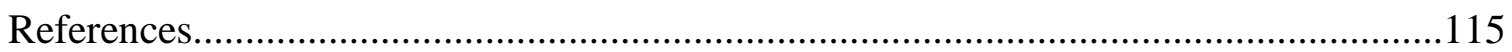




\section{List of Appendices}

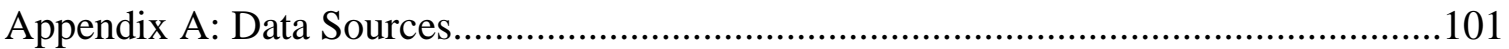

Appendix B: Rationales Aligning with Social Investment Discourse..............................104

Appendix C: Rationales Aligning with Social Justice Discourse......................................107

Appendix D: Rationales Aligning with Social Justice Discourse and Social Investment

Discourse

Appendix E: Figures Demonstrating Frequency of Social Investment, Social Justice and

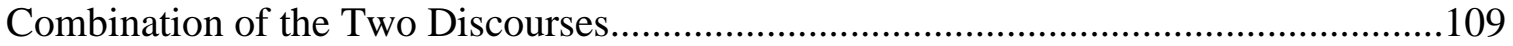

Appendix F: Frequency of Discourses According to Genre............................................111

Appendix G: Frequency of Discourses According to Date.............................................112

Appendix H: Texts Used for CDA..............................................................113 


\section{Chapter 1: Introduction}

\section{Purpose of the Study}

In 2010 the Ontario Liberal government introduced the full-day early learning Kindergarten (FDK) program, which the Ontario Ministry of Education (2014) claims is "the single most significant investment in education in a generation..." (p. 2). FDK was established to provide children aged four and five in the province of Ontario with universal access to full-day education programming and extended care (Pascal, 2009). According to Pelletier (2013): "the policy is bold in terms of the dollars committed, and in terms of the innovations of an "integrated" program for early learning and child development, not simply a doubling of time in school for 4- and 5-year olds" (p.2). Friendly (2008) argues that the introduction of FDK in Ontario could have important national implications as the successful implementation of this program could provide a foundation for integrating early childhood services across Canada.

Despite the significance of Ontario’s FDK policy initiative, there is a lack of clarity in the literature regarding the central aim of FDK, as its development has been traced to multiple and at times, disparate rationales. For example, Cantalini-Williams and Telfer (2010) hold that support for the adoption of the FDK program is based on the significance of early childhood to individuals' life-long development. In addition to discussing the FDK program's capacity to support children's development, Pelletier (2013) states that FDK seeks to promote children's competence within the education system, their future participation in the economy, as well as to advance equitable access to opportunities for all children and families. Furthermore, Bundy (2012) proposes that the justification for changing Ontario's early years system has been "framed within the discourse of 
investment, equality of opportunity and the importance of childhood education, all of which are 'proven' through research and scientific study" (p. 594). It is important to note that while the above authors indicate why FDK was implemented, there is a lack of research focused on analyzing how the program is rationalized in Ontario government texts.

The multiple explanations within the academic literature as to why FDK was implemented and what the program aims to achieve is reflective of the broader debate in Canada regarding support for early childhood services. According to Friendly (2006), Canada lacks a concise articulation of the central aims of early childhood programming, as well as whom these programs are ultimately meant to serve. Within the past twenty years, the rationales for early childhood services in Canada "have swung back and forth from life-long learning, school readiness and child development to employability, to women's equality, balancing work and family, reducing poverty, alleviating at-risk status and social integration" (Friendly, Doherty, and Beach 2006, p.4). Friendly (2006) argues, that this lack of a clear vision for early childhood policy sets Canada apart from more advanced early childhood programming. Langford, Prentice, Albanese, Summers, Messina-Goertzen and Richardson (2013) also discuss the diverse rationales for childcare within the advocacy community. Langford et al. (2013) reveal how Canadian childcare advocacy groups have identified childcare as supporting children's development, working parents, the future workforce, the economy, as well as alleviating poverty.

This diversity in rationales supporting early childhood services is also demonstrated at the international level. White's (2011) analysis of how international organizations are framing early childhood policies finds that there is a rising prevalence of a human capital 
rationale for ECEC, as well as the presence of additional frames, such as supporting children's rights; supporting parents' and particularly women's participation in work and setting forth a social pedagogical approach to ECEC.

Amidst a policy and advocacy landscape reflecting multiple rationales regarding the purpose of early childhood services (Friendly et al., 2006; Langford et al., 2013; White, 2011), the investment-oriented, economic discourse for supporting early childhood programming has gained prominence in both the Canadian and international context (Adamson \& Brennan, 2014; Bundy, 2012; Jenson \& Saint-Martin, 2003; Morel, Palier \& Palme, 2012; Nolan, 2013; Prentice, 2009). Bundy (2012) argues that the surge in national governments' focus on enhancing the provision of early childhood services has paralleled the framing of childcare as a public investment. As briefly mentioned, Bundy (2012) also argues that the social investment frame was fundamental to the rationalization of Pascal's vision for the Early Learning Program. Furthermore, Prentice (2009) argues that the justification for childcare has shifted from an earlier emphasis on supporting maternal employment to a contemporary focus on enhancing society's broader economic growth and well-being.

The central premise of social investment welfare state strategies is that states should engage in active social policy, which seeks to support individuals for participation in paid employment (Jenson and Saint- Martin, 2003). As such, the social investment model articulates that states play an important role in supporting individuals' human capital development and molding future citizens (Bundy, 2012). Within this framework, early childhood programming becomes a particularly important expenditure for the state, as it is seen as "the foundation for lifelong learning" (Bundy, 2012, p. 594), as well as a means 
of supporting parents' child-rearing capacities (Mahon, 2008). The social investment model also views early childhood programming as valuable due to research demonstrating that expenditure on the early years constitutes a more financially lucrative investment than expenditure on services for older populations (Jenson \& Saint-Martin, 2003).

The social investment discourse for ECEC policy development has received support from international organizations, such as the Organization for Economic Development and the World Bank (Mahon, 2010), scholars, such as Esping-Andersen (2002) and Giddens (1998), as well as American, Nobel prizewinning economist James Heckman (2011). Prentice (2009) identifies how the rationale for investing in the care and education of children is also set forth by experts working in the field of health, who articulate the important impact of early childhood programming on human health and development. Bundy (2012) also argues that scientific evidence and expertise are fundamental to establishing the social investment approach and discourse supporting early childhood policy development. Dobrowolsky and Saint-Martin (2005) outline how the federal Liberal party during former Prime Minister Jean Chrétien's Liberal government employed social investment discourse, particularly in relation to early childhood services.

While many scholars highlight the potential benefits of the social investment approach to designing public policy, other scholars have explored the complexities and limitations of employing this frame in order to advance progressive early childhood and family policy (Prentice, 2009; Williams, 2010a). In analyzing the implications of the social investment model, Prentice (2009) articulates how "the investable child—as frame 
and remedy_ both enables and forecloses political choices" (p.703). On the one hand, the economic rationale for investing in childcare has enhanced the scope of support for providing funding for childcare and to a certain degree has even resulted in enhanced service provision (Prentice, 2009). Williams (2010a) also concedes that this discourse “creates political spaces in which claims for improvements in children's and women's lives can be articulated" (p.19). On the other hand, this approach fails to adequately support gender equity advocacy (Prentice, 2009), as well as fails to address the systemic problems that have resulted in children facing socio-economic disadvantage and women's inequitable employment circumstances (Williams, 2010a). Furthermore, the rise of social investment discourse has served to silence advocacy that supports broader, emancipatory change (Williams, 2010a).

In light of the growing prevalence of the social investment discourse in supporting early childhood services nationally and internationally (Adamson \& Brennan, 2014; Jenson \& Saint-Martin, 2003; Morel et al., 2012; Nolan, 2013; White, 2012), as well as the lack of Canadian consensus regarding the purpose of early childhood programming (Friendly et al., 2006), it is important to explore how early childhood policy development is being framed in Canada. As previously mentioned, the implementation of FDK in Ontario constitutes a significant policy initiative due to its expense, the changes that it has made to the provision of early childhood services (Pelletier, 2013), as well as its potential implications for early childhood policy development throughout Canada (Friendly, 2008). As a result, examining the Ontario government's recent dissemination of FDK provides a valuable opportunity to gain a deeper understanding of how early childhood policy is 
being framed in this province, as well as the role of the social investment discourse in this process.

It is also important to explore the Ontario government's rationalization of FDK in Ontario in order to support democratic discussion regarding this policy initiative and its impact on Ontarians. According to Moss (2007), there is a need for democratic deliberation concerning the influence that enhanced policy developments and government spending on early childhood services, such as the FDK program, have on advancing citizens' interests and supporting educational outcomes for children. In a democratic society, it is fundamental that citizens participate in decision-making regarding their vision for how public expenditure on early childhood programming can best support the needs and well being of children, families and the broader community (Moss, 2007).

Therefore, the purpose of this paper is to apply a critical discourse analysis (CDA) of twenty-two publicly available government documents to examine how the Ontario government rationalized this policy to the public. This paper will explore the implications that these findings hold for equitable and socially just early childhood policy in Ontario, as well as one's understanding of the government's responsibilities for and relationship with its citizens.

\section{Research Questions}

In exploring the topic of the Ontario government's rationalization of FDK, this study aims to address four research questions. As a result of the multiple rationales for early childhood programming in Canada identified in the literature (Friendly, Doherty, \& Beach 2006; Langford et al., 2013), the study will first seek to establish: What rationales has the Ontario government drawn on to justify FDK to the public? Next, due to the 
increasing significance of the social investment model in framing early childhood policy (Adamson \& Brennan, 2014; Bundy, 2012; Dobrowolsky \& Saint-Martin, 2005; Jenson \& Saint-Martin, 2003; Morel et al., 2012; Nolan, 2013; White, 2012) this study will seek to answer: How prevalent is the social investment discourse in the Ontario government's rationalization of FDK to the public? In addition, this study will ask: What additional discourses regarding social citizenship have been drawn on in the rationalization of this policy? Finally, this study will examine: What practices within the structure and language of the text have been employed to support the social investment discourse?

\section{Theoretical Framework}

CDA constitutes both a methodological approach as well as a theoretical framework (Fairclough, 2010). This study will adopt the approach to CDA set forth by Fairclough $(1995 ; 2000 ; 2003 ; 2010)$. A central premise underlying Fairclough's (2003) framework is that "language is an irreducible part of social life, dialectically interconnected with other elements of social life, so that social analysis and research always has to take account of language" (p. 2). Fairclough (2003) states, "texts have social, political, cognitive, moral and material consequences and effects" (p. 14) and goes on to argue, "it is vital to understand these consequences and effects if we are to raise moral and political questions about contemporary societies..." (p.14).

Fairclough's (2010) approach to CDA is centered on a critical realist framework, and 'a 'moderate' or contingent' form of social constructivism" (p. 5). Fairclough's (2010) approach focuses on understanding social reality through examining how discourse represents the social world in particular ways and the implications these representations hold for conceptualizing and approaching social problems and change. 
However, any attempt to analyze and gain a deeper understanding of reality is always incomplete and dependent on one's own particular perspective and approach (Fairclough, 2003). A core feature of this perspective is that "the world is discursively construed (or represented) in many and various ways, but which construals come to have socially constructed effects depends upon a range of conditions which include for instance power relations but also properties of whatever parts or aspects of the world are being construed" (Fairclough, 2010, p. 4-5). Therefore, certain attempts to foster social change can be realized, whereas others cannot (Fairclough, 2010).

Fairclough's (2000) work has also focused on analyzing how social investment or as he calls it, third way discourse, was employed by the New Labour Party during the administration of former Prime Minister of the United Kingdom, Tony Blair. As a result, Fairclough's (2000) theoretical and methodological approach to CDA is particularly valuable for this study's focus on examining the prevalence of social investment discourse in the Ontario government's discursive representation of FDK. In addition to CDA, a combination of the feminist ethics of care and social justice approaches, as set forth by Williams (2010a; 2010b), has also provided the foundation for developing this study and will be incorporated in critically analyzing the implications of its findings for children and families' care claims and social citizenship. This section will now briefly define care theory and then explore how care theory and social justice have been reconciled within this study's analysis.

Care theory sets forth an alternative understanding of human morality and decisionmaking to traditional, liberal theories of justice (Cockburn, 2005; Held, 2005). Care theorists oppose the liberal, ethic of justice's portrayal of humans as autonomous, 
rational, rights-bearing individuals, who make moral decisions by adhering to universal, abstract principles (Cockburn, 2005; Held, 2005). Instead, the feminist ethics of care views humans as relational and interdependent and values emotions. Care theorists also emphasize the importance of attending to context and relationships and supporting others' needs in moral decision-making (Cockburn, 2005; Held, 2005). Moreover, care theorists reject the future-oriented approaches to conceptualizing support for children, and instead, focus on children's wellbeing in the present context (Cockburn, 2005).

As briefly indicated, this study will seek to reconcile an ethic of care approach with a social justice approach to care policies and social citizenship, as set forth by Williams (2010a; 2010b). Williams (2010a; 2010b) offers an approach to understanding social justice and care claims in relation to the state that is beneficial to this study. The social justice approach supports acknowledging marginalized groups in care policy, honouring the rights of these groups in relation to receiving and providing care, as well as redistributing the power, responsibility and resources in relation to care work and decision-making (Williams, 2010a). As such, Williams’s (2010a; 2010b) approach reconciles care and justice by indicating how social justice framing supports individuals' and groups' care claims and supports the well-being of care receivers and providers. Furthermore, Williams (2010a; 2010b) distinguishes this social justice and care-oriented approach from a social investment-oriented framing of care policy. On the one hand, Williams (2010b) sheds light on the limitations of a social investment approach to addressing structural barriers that undermine citizens' well-being. On the other hand, Williams (2010b) offers nuanced insight regarding the potential benefits of social 
investment in supporting state expenditure on programming that can realize social justice outcomes.

Like Williams (2010a; 2010b), Tronto (2013) also offers an understanding of the intersection between care and justice. Tronto (2013) argues all human beings depend on the care of other individuals. It is this interdependency and universal need for care that provides the foundation for equality in democratic societies (Tronto, 2013). For Tronto (2013):

Our political responsibility to other citizens, which is how we might define justice, is that we must ensure that, in our democracy, no one goes without care. Justice thus comes from the public decisions about caring responsibilities that we make collectively (p. 62).

Democratic societies must enable citizens to: participate in collectively identifying care needs and resulting responsibilities; determining who is responsible for meeting these needs; and establishing whether or not these responsibilities have been upheld (Tronto, 2013).

Tronto (2013) provides a conceptualization of the relationship between care responsibilities, citizenship and justice that seems compatible with Williams's (2010a; 2010b) framework for analyzing citizens' care claims. However, Williams's (2010a; 2010b) reconciliation of care and justice has ultimately informed this study's analysis due to her focus on comparing this approach with social investment.

Therefore, a combination of the feminist ethics of care and a social justice approach to understanding social citizenship claims in relation to care, as offered by Williams (2010a; 2010b), along with CDA has informed the purpose of this study. This study will 
apply this theoretical framework in order to examine how the Ontario government justifies FDK and the implications this holds for supporting the well-being and rights of children and families. This overarching theoretical framework will also be applied to exploring the potential possibilities and limitations of the social investment-oriented representation of FDK, as well as the opportunities to advance more social justice and care-oriented claims in support of early childhood policy development and the state's responsibility to provide education and care programming for all children and families.

\section{Position of the Researcher}

In applying CDA as a research approach, it is fundamental that the researcher explicitly identifies and reflects upon their position in relation to the research (Breeze, 2011; Fairclough, 2003). The concern that many authors have demonstrated regarding the increased prevalence of a social investment-oriented justification for early childhood policy has inspired this research (Bundy, 2012; Cantillon \&Van Lancker, 2013; Prentice, 2009, Williams, 2010a). The researcher is concerned with the potential that social investment discourse could have in limiting more social justice-oriented representations and practices in early childhood policy development (Prentice, 2009; Williams, 2010a).

The researcher has experience working on children's rights advocacy initiatives, through their previous role as a Research Assistant with the Ghana Commission on Human Rights and Administrative Justice and through their ongoing membership in the Canadian Student Association for Children's Rights. These experiences have informed the researcher's perception of the benefits and challenges of employing human rights discourse in order to promote justice, particularly for vulnerable populations. 
While the researcher's experience in the field of children's rights has inspired this study, the researcher is also concerned with the dominance of this discourse in conceptualizing children's advocacy and the potential limitations of this approach (Cockburn, 2005). The researcher has developed an academic interest in the feminist ethics of care through their previous role as a Graduate Assistant in the course: "A Caring World for Children." The researcher's experience and interest in children's rights and the feminist ethics of care have led to the intent of this study to reconcile these frameworks, using Williams's (2010a; 2010b) approach, in order to explore how the rights and needs of children and families are represented in the Ontario government's rationalization of FDK to the public. 


\section{Chapter 2: Historical Background of FDK}

In order to provide a foundation for examining how the Ontario government rationalized FDK to the public, it is first necessary to review the emergence, key features, critiques and early outcomes of Ontario's FDK program. This discussion aims to situate FDK within the broader context of ECEC policy development and advocacy at the provincial, federal and international level.

\section{Emergence of the FDK Program in Ontario}

To begin, Turgeon (2014) establishes a comprehensive overview of how the FDK initiative is rooted in an extensive advocacy history supporting the development of integrated early childhood education and childcare services in the province of Ontario. From around the 1980s onwards, ECEC activists in Ontario began promoting the integration of childcare, education, as well as family services within a centralized location, known as a 'hub' (Turgeon, 2014). However, Ontario's Conservative government in the 1990s, led by former Premier Mike Harris, opposed the growth of early childhood service provision. Despite this opposition, the Conservative government called for McCain and Mustard (1999) to complete the Early Years Study (Turgeon, 2014). This study outlined research regarding the important developmental changes that occur during childhood and articulated the long-term value of investing in support for healthy early childhood development (McCain \& Mustard, 1999). In addition, McCain and Mustard's (1999) study provided the Ontario government with recommendations for developing a comprehensive system of programming to support children and families. According to Richardson (2011), McCain and Mustard's (1999) work has "reinforced the popular idea that high quality, developmentally appropriate stimulation during early 
critical periods of development is essential to maximize potential in all developmental domains" (p.9).

While the Conservative government pursued some of the changes recommended by McCain and Mustard (1999), over all there was a lack of progress towards establishing an integrated provincial ECEC system (Turgeon, 2014). Turgeon (2014) provides examples of some of the school boards, such as Peel County and projects within the Toronto District school board, such as Toronto First Duty (TFD), which adopted integrated approaches to service provision despite the limited provincial support. The TFD project and the Best Start program have been identified in the literature as influencing the provincial implementation of FDK (Friendly, 2008; Turgeon, 2014).

At this time, early childhood advocates also aligned with international advocacy initiatives and organizations, such as the Organization for Economic Co-operation and Development (OECD) (Turgeon, 2014). The OECD's review of ECEC in Canada "strengthened a 'child-centered' frame which articulated the link between integrating 'care' and 'education'" (Colechin, 2010, p.169). This review also created political space for different Canadian childcare advocacy groups and agendas to join in a "holistic frame for (policy) action" (Colechin, 2010, p. 169). Turgeon (2014) argues that the OECD's approach to ECEC influenced the former Liberal Premier of Ontario, Dalton McGuinty, who was elected in 2004, to prioritize the implementation of FDK.

In discussing the emergence of the FDK program, it is fundamental to identify the influence of Dr. Charles Pascal, who was a special advisor on Early Learning for Premier McGuinty. Pascal's (2009) report, With Our Best Futures in Mind, Implementing Early Learning in Ontario, outlines research regarding the importance of the early years in 
supporting children's long-term education and growth. Pascal's (2009) report also establishes a strategy for the Ontario government to implement significant changes to the ECEC system in Ontario. Turgeon (2014) states that Pascal's (2009) report has resulted in the establishment of FDK, although the current program does not entirely reflect the vision set forth by Pascal (2009).

\section{Overview of the FDK Policy Initiative and Program}

While the previous discussion highlighted how FDK came to fruition, the focus will now turn to outlining the key features of this program. FDK is being gradually implemented over five years, with its aim to be fully accessible to children aged four to five in Ontario in 2015 to 2016 (Turgeon, 2014). Pascal (2009) sets forth a vision for Ontario's child services integration plan, which establishes "a single program with a single pedagogical and curriculum approach planned and delivered by qualified educators using common space and resources" (p. 18). In order to establish this policy initiative, the government of Ontario passed the Full Day Early Learning Law Amendment Act, 2010, also known as Bill 242 (Turgeon, 2014). This legislation allows school boards to offer full day education programming, as well as extended day programming to students aged four and five (Cantalini-Williams \& Telfer, 2010). In order to support the successful integration of ECEC services, the Ministry of Education has taken over the jurisdiction of childcare policy from the Ministry of Children and Youth Services (Turgeon, 2014).

The FDK program was accompanied by the release of The Full-Day Early Learning-Kindergarten Program (Draft Version) (2010-2011) curriculum, which replaced The kindergarten Program, 2006 (Revised) curriculum (Ontario Ministry of Education, 2010a). This new curricular approach is founded upon an inquiry-based 
learning framework (Gananathan, 2011). FDK also intends to adopt a play-based pedagogical model, which Pelletier (2013) views as a unique feature of the program, as it constitutes a significant transition from a teacher-focused approach. Pelletier (2013) claims that another innovative characteristic of the FDK program is that it is led by a teaching team, which consists of a teacher and an early childhood educator. This approach to service provision seeks to combine "the expertise of both professional early educators to optimize early child development" (Gananathan, 2011, p. 33).

The above changes that have been brought about with the introduction of FDK reflect the Ontario government's efforts to implement a "comprehensive early learning system" (Gananathan, 2011, p.33). Education and care programs have traditionally constituted distinct domains, with different structures, guidelines, approaches and aims in order to support children and families (Turgeon, 2014). However, the FDK program's integrated approach to service provision for four and five year olds is reflective of a growing Canadian and global movement towards service integration in early childhood education and care (Gananathan, 2011).

It is important to note that the introduction of the FDK program in Ontario has been met with debate and opposition, "with some political actors and commentators objecting to the cost, design, and even philosophy of the program" (Turgeon, 2014, p. 225). For example, the Conservative Party of Ontario initially did not support the Ontario Liberal government's implementation of FDK and has recently argued that the government should refrain from further developing the program until the fiscal deficit has been addressed (Turgeon, 2014). 
Bundy (2012) provides a much different critique of the program by arguing that Pascal's framework for implementing Ontario's integrated early years system fails to support gender equality. Bundy (2012) looks at three policy documents that Pascal produced for former Premier of Ontario Dalton McGuinty, outlining his vision for changes to Ontario's early learning system. Bundy (2012) argues that Pascal's vision for the program reflects a "scientisation of early learning and care" (p. 599), as it draws on child development research to outline education practices that "are meant to guarantee a very particular type of citizen: a highly educated citizen, capable of continuing and lifelong education, who can be flexible in an uncertain, knowledge-based job market" ( $p$. 599).

Bundy (2012) maintains that the vision of early childhood education and care set forth by Pascal is centered on a social investment rationale, as it emphasizes the societal and economic benefits of investing in early childhood programming. Bundy (2012) also describes Pascal's emphasis on the importance of parent involvement in the early learning program and their development of quality parenting skills. As a result, Bundy (2012) contends that Pascal's framework for the early years and its social investment rationale is reflective of a biopolitical apparatus, whereby the state seeks to use early childhood programming to mould children into a particular type of future citizen and to regulate their parents to support this goal.

\section{Early Outcomes of the FDK Program}

According to Pelletier (2013), her findings regarding FDK at the end of the third year of implementation suggest positive outcomes for children participating in the program in relation to their vocabulary development and self-regulation skills. In 
addition, the findings suggest that involvement in the program resulted in teaching teams identifying positive professional outcomes, parents feeling less stressed and children valuing the opportunities to engage in play (Pelletier, 2013).

This study seeks to build on the above-mentioned literature regarding the introduction of FDK in Ontario and particularly, Bundy's (2012) analysis of the prevalence of the social investment discourse in Pascal's policy documents, which influenced the implementation of the FDK program. In doing so, this study aims to address a gap identified in the literature, as there has not been research examining how the Ontario government has rationalized FDK to the public through key political speeches and policy documents. The following chapter will establish the foundation for pursuing the research by reviewing literature regarding rationales and underlying discourses for understanding and justifying public expenditure on early childhood policy. 


\section{Chapter 3: Literature Review}

The purpose of this literature review is to examine different rationales for early childhood policy development and underlying discourses for social citizenship that previous research has identified. Furthermore, this literature review aims to present previous research that has been conducted examining rationales and discourses supporting FDK, in order to situate this study within this broader context. This discussion will begin by examining two broad models for citizenship regimes, social investment and social justice, as identified by Jenson and Saint-Martin (2003). Upon outlining these overarching models for understanding social citizenship, the review will discuss the emergence of the social investment approach to social policy, as well as briefly outline debates regarding its conceptual meaning and practical implementation.

This review will then provide a brief outline of political framing and its relationship to discourse. Finally, this review will critically examine different rationales for supporting early childhood policy, which have been grouped within social justice and social investment discourses. Ultimately, this literature review seeks to support this study's focus on examining how FDK is being rationalized to the public, as well as how the social investment and social justice discourses are reflected within this rationalization.

\section{Social Investment and Social Rights Models of Citizenship}

In order to discuss different discourses justifying early childhood policy, it is first necessary to establish an understanding of changes to the overarching welfare state and citizenship. Jenson and Saint-Martin (2003) define citizenship regimes as "institutional arrangements, rules and understandings that guide and shape concurrent policy decisions and expenditures of states, problem definitions by states and citizens, and claims-making 
by citizens" (p. 80). The authors argue that citizenship regimes are characterized by the way in which states establish and weigh their responsibilities for the welfare of citizens with the market, the family and the larger community, as well as how states address citizens' rights and responsibilities (Jenson \& Saint- Martin, 2003).

Jenson and Saint-Martin (2003) identify two models of citizenship, which include a social rights approach and a social investment approach. Within both models, the primary source of citizens' welfare protection stems from participation in the labour market (Saint-Martin, 2003). However, the state also has a responsibility for safeguarding the welfare of its citizens (Jenson \& Saint-Martin, 2003). Jenson and Saint-Martin (2003) hold that the state's approach to supporting the security of its citizens is central to distinguishing citizenship regimes.

Social Rights Model of Citizenship. The social rights approach to citizenship emerged in the post-1945 era and focuses on protecting the welfare, equality and rights of its citizens (Jenson \& Saint-Martin, 2003). Within the social rights citizenship regime, the primary aim of the state was to support the economy and ensure citizens have access to work (Jenson \& Saint-Martin, 2003). In addition, the state was responsible for protecting citizens' rights and supporting equality through policy development and redistribution measures (Jenson \& Saint-Martin, 2003). The social rights citizenship regime model ultimately offers protection to its citizens from the inequality and hardship that can result from market forces (Jenson \& Saint-Martin, 2003).

Social Investment Model of Citizenship. Before discussing how Jenson and Saint-Martin (2003) define the social investment citizenship regime, it is useful to outline how this approach to welfare state policy emerged. For Morel, Palier and Palme (2012), 
the rise of the social investment approach reflects the continuous evolution of the welfare state. The social investment framework gained prominence in the 1990s and sought to offer an approach to welfare state policy that addressed the new challenges and concerns raised by changes in the economy and society (Hemerjick, 2011; Morel et al., 2012). In particular, social investment is envisioned as an approach to social policy that can best meet the needs and demands brought about by the shift towards a knowledge-based economy (Morel et al., 2012). Morel et al. (2012) state this new economy is supported by the knowledge and skills of the workforce. Fairclough (2003) also usefully explains that in a knowledge economy and society, "change comes about, at an increasingly rapid pace, through the generation, circulation, and operationalization of knowledges in economic and social processes” (p. 207). Bonoli (2005) and Esping-Andersen (2002) further hold that the contemporary welfare state must address new social challenges that individuals, families and communities are confronted with in relation to protecting their security and welfare. Therefore, the social investment approach has emerged as a framework for supporting economic progress within the knowledge-based economy, as well as supporting individuals' and families' welfare in relation to new challenges (Morel et al., 2012).

The literature also identifies that the social investment approach is understood as both a transition away from neo-liberalism and a continuation of some of its key principles. Nolan (2013) says the social investment perspective has received support as a different approach to responding to the global economic downturn and the rise of the knowledge-based economy than neo-liberalism. Adamson and Brennan (2014), as well as Jenson and Saint-Martin (2003) assert that the social investment approach opposes neo- 
liberalism's understanding of government spending on social policy as economically unproductive. Mahon (2008) elaborates on this distinction, saying while neo-liberalism emphasizes limiting government regulation of the market and supporting a market-based approach to the provision of social services, social investment views some government expenditure on social policy as useful for supporting citizens.

Other authors present a different characterization of the relationship between social investment and neo-liberalism. While Jenson and Saint-Martin (2003) argue that the social investment approach has challenged certain ideas set forth by neo-liberalism, but also claim that this framework has upheld neo-liberalism's emphasis on the state supporting economic advancement. Bundy (2012) holds that the social investment approach maintains neo-liberalism's emphasis on limited public expenditure on social services but articulates that the funding that the government does provide should be focused on supporting individuals' productive capacity. Thus, the literature presents different interpretations of the extent to which the social investment approach diverges from neo-liberalism.

Now that this review has established the political and economic context through which the social investment approach emerged, as well as debates regarding its distinction from neo-liberalism, the focus will turn to outlining Jenson and Saint-Martin's (2003) characterization of social investment as a citizenship regime. The social investment citizenship regime is based on the premise that in order to build security for citizens, it is necessary to ensure they are adequately prepared for future success and to respond to new labour market demands, particularly as a result of global capitalism (Jenson \& Saint-Martin, 2003). Thus, this approach values active, future-oriented social 
policy that supports citizens' human capital development, particularly in the early years (Jenson \& Saint-Martin, 2003). Jenson and Saint-Martin (2003) claim that the social investment framework places stronger emphasis on protecting citizens' "equality of opportunity for future success" (p. 92), as opposed to promoting the realization of equality in the contemporary context. Ultimately, this model of citizenship understands preparing and supporting citizens, particularly children, for participation in paid employment as the best means of protecting their welfare (Jenson \& Saint-Martin, 2003).

Debates Regarding Social investment: In Theory and Practice. Jenson and Saint-Martin (2003) establish that their presentation of the social investment and social rights citizenship regimes, as outlined above, represents "ideal types" (p.82). Therefore, it is important to further examine questions raised in the literature regarding the theoretical conceptualization and practical implementation of the social investment approach to welfare state policy. Nolan (2013) provides a critical discussion of the multiple and complex ways in which social investment can be conceived: "as a paradigm and strategy for social policies and spending, as a conceptual base and analytical framework, and/or as a platform for political engagement...” (p.467).

Although it is beyond the scope of this paper to offer an extensive exploration of the diverse ways in which social investment is conceptualized and implemented in policy, it is necessary to briefly address this topic. This discussion will also seek to establish how social investment will be understood in the context of this paper.

Within a paradigmatic definition, social investment is understood as a template for determining how states should design and implement welfare state policy (Nolan, 2013). White (2012) usefully employs Hall's (1992) definition of policy paradigms in her 
discussion as to whether social investment can be considered paradigmatic. Hall (1992) defines policy paradigms as an:

Overarching set of ideas that specify how the problems facing (policy makers) are to be perceived, which goals might be attained through policy and what sorts of techniques can be used to reach those goals. Ideas about each of these matters interlock to form a relatively coherent whole (p. 91-92).

White (2012) claims that, "To demonstrate that policy ideas are paradigmatic, one has to show that they are widespread, have a taken-for-grantedness, and that they filter out other options (that is, they become normative)" (p. 660).

It is important to note that certain scholars have questioned whether social investment can be characterized as a paradigm (Morel et al., 2012; White, 2012). Morel et al. (2012) hold that changes are occurring within approaches to social policy in different countries that reflect a social investment model. However, these authors remain hesitant to define these changes as reflective of a concrete social investment paradigm (Morel et al., 2012). White (2012) also questions the paradigmatic status of social investment by examining early childhood programming, as well as parent-support programs in liberal nation-states. White (2012) ultimately argues that the changes to services for children and families cannot be considered representative of a shift towards a social investment paradigm due to the diverse nature of the design and implementation of these policies and the increasing reliance on market-provision.

Like White (2012), Adamson and Brennan (2014) also articulate the rise of the social investment discourse for supporting expenditure on early childhood has not been fully realized in practice. Adamson and Brennan (2014) examine the cases of early 
childhood service provision in the United Kingdom and Australia. Adamson and Brennan (2014) find that although the United Kingdom and Australia have promoted social investment discourse in support of early childhood policy development, in practice, these countries have undermined social investment strategies through their reliance on private service provision. Adamson and Brennan's (2014) analysis points to the discrepancy that can exist between governments' use of social investment discourse and their design and implementation of early childhood policy.

Morel et al.'s (2012) characterization of two distinct social investment models provides further insight regarding the variation in the social investment approach in both theory and practice. These models include a social democratic and a third way approach to social investment (Morel et al., 2012). The social democratic approach is endorsed by scholar Gosta Esping-Andersen (2002) and reflected in the policies of Nordic countries (Morel et al., 2012). In contrast, the third way approach is promoted by Anthony Giddens (1998) and reflects the policy approach adopted by liberal, Anglo-Saxon countries (Morel et al., 2012). Morel et al. (2012) establish that the key distinction between these models is centered on the state's responsibility in relation to social protection. The social democratic approach places continued importance on the state maintaining social protection mechanisms (Morel et al., 2012). However, the third way model is focused more strictly on policies that support individuals' participation in the labour-market and productivity (Morel et al., 2012). Adamson and Brennan (2014) also draw on the work of Morel et al. (2012) and Morgan (2009) to identify how these models affect different orientations towards early childhood policy, which will be discussed in further detail below. 
Now that this literature review has addressed the above debate regarding whether social investment constitutes a paradigm and how social investment approaches vary in practice, the focus can turn to establishing how social investment will be understood for in the context of this study. Instead of conceiving of social investment as a policy paradigm, this study will adopt an understanding of social investment as a political and policy advocacy discourse, as highlighted by Nolan (2013), Morel et al. (2012) and Fairclough (2000). Nolan (2013) discusses this conceptualization of social investment as set forth by scholars such as Morel et al. (2012), whereby social investment is understood as a political approach for asserting the value of public expenditure on social welfare and challenging arguments for limiting spending. As a political and policy advocacy discourse, social investment must be able to appeal to important stakeholders (Nolan, 2013). In particular, social investment needs to persuade the more traditional economic camp to believe social policy expenditures hold economic value (Nolan, 2013).

\section{Political Framing and Discourse}

In order to examine social investment along with other discourses and underlying rationales for supporting the expansion of early childhood services, it is fundamental to briefly explore the relationship between framing and discourse. Hajer (1993) discusses the importance of language and discourse in the construction and framing of political and social problems. Hajer (1993) defines discourses as "an ensemble of ideas, concepts, and categories through which meaning is given to a phenomenon" (p.45). Hajer (1993) goes on to argue that discourses frame problems by "distinguish(ing) some aspects of a situation rather than others" (p.45). Prentice (2009) states that frames are set forth as 
"whole arguments" (p. 689) and tell individuals "not just what to think but how to think about something" (p. 689).

Lakoff (2014) applies cognitive science to provide insight regarding the role of framing in political representations and interpretations of social problems. According to Lakoff (2014); "Frames are mental structures that shape the way (one) see(s) the world..." (p. xi) and are set forth through the use of language. Lakoff (2014) further articulates that frames influence the development and implementation of public policies. Ultimately, Lakoff (2014) argues that through the process of reframing social and political issues and problems, one can contribute to changing individuals' conceptions of social reality.

Now that this review has established the relationship between framing and discourse, the next section will seek to provide a detailed outline of different frames or rationales for understanding early childhood policy development that can be grouped within social investment and social justice discourse.

\section{Social Investment Discourse for Early Childhood Policy}

Children are fundamental to the social investment discourse, "both as an emblem of the future and as a potential barrier to mothers' employment in the here and now" (Adamson \& Brennan, 2014, p.47). As a result, the provision of childcare is fundamental to a social investment policy approach (Morgan, 2009). The social investment framework prioritizes early childhood programming as a means of supporting children to become successful adults, as well as supporting parents to access paid employment and in turn, reduce poverty and advance social inclusion (Jenson \& Saint-Martin, 2003). 
Before turning to the more specific rationales that the social investment discourse sets forth in articulating the need for early childhood policy development, it is important to highlight Adamson and Brennan's (2014) distinction between two different models and sets of rationales for early childhood policy that have been established within the broader social investment approach. Adamson and Brennan (2014) draw on the work of Morel et al. (2012) and Morgan (2009) to articulate how the social democratic approach to social investment and the third way or Anglo-Saxon approach to social investment set forth different approaches and rationales for early childhood policy. Canada, along with Australia and the United Kingdom fall under the third way model, whereby investing in early childhood programming is supported by a human capital- centered rationale (Adamson \& Brennan, 2014). This approach differs from a more social democratic model of social investment, adopted by Nordic countries, which emphasizes the important role of ECEC in advancing social equality (Adamson \& Brennan, 2014). It is noteworthy that the social democratic model of social investment and its emphasis on supporting social equality and rights seems to share similarities with the social justice approach to social citizenship and care policies discussed by Williams (2010a; 2010b) and incorporated in this paper's analysis. Now, that this distinction has been outlined, the focus of this review will turn to identifying the different rationales for early childhood services that have been grouped under a broader conceptualization of social investment discourse.

Supporting Human Capital Development. As briefly established, the central aim of the social investment approach is to support individuals' employment (Jenson \& SaintMartin, 2003). Participation in paid labour is seen as the most effective mechanism for protecting individual and collective well-being by reducing citizens' reliance on welfare 
benefits and enhancing their ability to contribute to economic progress (Cantillon \& Van Lancker, 2013; Hemerjick, 2011; Jenson \& Saint-Martin, 2003; Nolan, 2013).

Within the social investment approach, programs that enhance human capital development, particularly in the early years, are understood as essential to preparing individuals for integration into the workforce (Esping-Andersen, 2002; Heckman, 2011; Hemerjick, 2011; Morel et al., 2012, Nolan, 2013). Individuals develop human capital by building their "skills, competencies and knowledge, such as literacy, numeracy, selfdiscipline and perseverance" (Riddell, 2007, as cited in White, 2012, p. 662).

The importance that social investment discourse places on supporting children's human capital development is connected to the rise of the knowledge-based economy (Morel et al., 2012). Esping-Andersen (2002) holds that in the knowledge-based economy, an individual's human capital is central to determining their capacity to maintain a decent standard of living. Moreover, workers' skills and knowledge are seen as fundamental to supporting economic progress (Esping-Andersen, 2002; Heckman 2011). Esping-Andersen (2002) and Heckman (2011) claim that the state must prepare children for participation in the knowledge-based economy in order to protect their welfare and advance broader social and economic well-being.

Heckman (2011) argues that children's cognitive and social development in the early years shapes their long-term socio-economic welfare and their ability to hold a "white-collar job" (p. 33). Thus, the social investment approach holds that the state should invest in early childhood programming that supports children to develop the skills, cognitive abilities and character traits that will prepare them for participation in the economy and prevent them from experiencing social exclusion (Esping-Andersen, 2002; 
Heckman, 2011). It is interesting to note what character traits Heckman (2011) identifies as indicative of future success: "perseverance, motivation, self-esteem, self-control, conscientiousness, and forward-thinking behaviour" (p. 33). The social investment approach also emphasizes a transition away from early childhood programming that is focused specifically on caring for children, towards a model that focuses on their learning and development (White, 2012).

Social investment not only places importance on investing in human capital development in early childhood, but also throughout the life course. Heckman (2011) argues that support for educational achievement should be continued through elementary school, high- school and postsecondary education. Social investment discourse also promotes lifelong learning in order to advance individuals' continued human capital development and in turn, access to opportunities (Cantillon \& Van Lancker, 2013; Jenson \& Saint-Martin, 2003; Morel et al., 2012; White, 2012).

On the one hand, one could argue that building individuals' human capital could be used in order to advance social justice goals and support. On the other hand, the human capital development discourse's emphasis on preparing citizens' to take responsibility for their own welfare and contribute to economic growth through gaining the education and skills to participate in paid labour arguably aligns this approach with social investment discursive representation of social citizenship and rationalization for early childhood programming. Instead of prioritizing the intrinsic value of education and care, the human capital development approach lends to an instrumentalization of children's education as a means to a more economic or productive oriented end (White, 2011; Woodhead, 2006). 
Supporting Children's Equal Opportunity. The social investment approach emphasizes the importance of providing "an equal start for all children alike" (Cantillon \& Van Lancker, 2013, p. 559). Social investment discourse is concerned with the impact that children's experiences of inequality and poverty can have in limiting their human capital development and restricting their future life chances, particularly in relation to accessing employment (Esping-Andersen, 2002; Van Lancker, 2013). Esping-Andersen (2002) claims that American research demonstrates the negative impact that experiencing child poverty can have on individuals' future chances of attaining success and social inclusion. It is noteworthy that Esping-Andersen (2002) does not provide the exact research being referenced to support this claim. In addition to the personal and social implications of child poverty, Esping-Andersen (2002) argues that poverty can foster a workforce that is less skilled and less able to maintain well-paying work and contribute to the welfare state. Services that seek to reduce child poverty thus become important within social investment discourse as a means of ensuring all children have the opportunity for academic achievement and a future as productive citizens (Jenson \& Saint- Martin, 2003; Esping-Andersen, 2002).

Heckman (2011) also argues that children's unequal access to a home environment that supports their development has detrimental consequences for their future life chances. Heckman (2011) further asserts, "Poor parenting is an important contributor to life poverty. But parenting deficits can be addressed. An equalizing factor is early access to education, which changes the equation for the parent and the child" (p. 33). Through providing children with equal access to support early in life, the social investment 
approach aims to reduce future vulnerability (Dobrowolsky \& Saint-Martin, 2005;

Esping-Andersen, 2002; Jenson \& Saint- Martin, 2003).

It is important to note that Esping-Andersen's (2002) discussion of addressing social exclusion and particularly poverty can be considered unique within social investment discourse, as he argues for combining both social protection measures, such as ensuring families have an adequate income, in addition to implementing policies that seek to support individuals' integration into the workforce. As Morel et al. (2012) highlight, this understanding of the need for social protection is characteristic of a more social democratic approach to social investment, as opposed to the third way, AngloSaxon approach.

Now that this review has set forth the emphasis that the social investment discourse places on ensuring equal access to opportunities for children, particularly in regards to education and human capital development, it is important to explore what conceptualization of equality this fosters. Bundy (2012) argues that the social investment discourse's emphasis on promoting equality through offering children a strong start in life is centered on an understanding of equality as: "equality of initial opportunity" (p. 595), which "must devolve with age to an outcome of individualised identity where inequality is based on one's own life choices and chances..." (p. 595). Similarly, Cantillon and Van Lancker (2013) allege that while the social investment approach values enhancing individuals' human capital and supporting their opportunities for success, individuals are ultimately expected to take ownership over protecting their own well-being. This can be differentiated from the social justice approach to social citizenship and care policy set forth by Williams (2010a; 2010b), which emphasizes individuals', families' and 
communities' entitlement to care and seems to establish an understanding of equality as centered in outcomes and not just opportunity.

Supporting Working Parents. The social investment approach not only values the contribution that early childhood programming can make to children's human capital development and equal opportunity for success, but also its capacity to support working parents (Morgan, 2009; Morel et al., 2012). While the social investment perspective focuses on supporting children to build human capital, in the case of parents, the focus is on ensuring they are able to apply their human capital through participation in the workforce (Morel et al., 2012). Nikolai (2009) claims that family-oriented social investment initiatives, such as the provision of early childhood programming, aim to support parents and particularly mothers, to have a family and maintain paid employment. Social investment also emphasizes the importance of early childhood programming as a means of reducing poverty by enabling parents to work and receive an income (Jenson \& Saint-Martin, 2003; Morgan, 2009). Morgan (2009) further holds that the provision of early childhood programming supports women to participate in paid employment by providing care for children while mothers are at work. As a result, this can help women to continue to utilize skills that may be jeopardized by absence from employment while providing care (Morgan, 2009). Therefore, ensuring families have access to childcare is important in the social investment model in order to facilitate parents' participation in the workforce and their capacity to support their family (Jenson \& Saint- Martin, 2003; Morgan, 2009).

Economic Benefits of Early Childhood Programming. Social investment advocates such as Heckman (2011) contend that supporting early childhood services will 
not only have positive benefits for children and parents, it will also support economic growth. Heckman (2011) avoids advocating for early childhood programming from an ethical standpoint and instead, emphasizes the potential that early childhood education can offer in advancing economic progress. Heckman (2011) states, "A large body of data from economics, biology, and psychology shows that educational equity is more than a social justice imperative; it is an economic imperative..." (p. 31). Heckman (2011) also holds that policies that support services for children from disadvantaged backgrounds can have the dual effect of achieving both economic and equitable outcomes. Here, one finds that Heckman's (2011) work is particularly focused on articulating the economic benefit of providing early childhood services to children and families from disadvantaged backgrounds.

Heckman (2011) argues that states' economic progress and position in the global economy depends on having a strong workforce. Referring to an American context, Heckman (2011) states, “Underdeveloped human potential burdens our economy and leaves us with a workforce that is less than it could be" (p. 31). However, social investment discourse's economic rationale for early childhood services stresses the potential return that early childhood programming offers as a publicly funded investment (Esping-Andersen, 2002; Heckman, 2011; Jenson \& Saint-Martin, 2003). Social investment discourse holds that investing in early years services is a more effective approach to fostering individual and economic productivity than policies that seek to support adults through, for example, integration into the labour market (Esping-Andersen, 2002; Heckman, 2011). Finally, Van Lancker (2013) asserts that "Investing in young children by means of qualitative childcare now pays large dividends in the future in tax 
revenues and forgone social spending, concomitantly contributing to sound public budgets" (p. 6).

It is important to note that previous research has identified the human capital and economic rationales outlined above as being distinct discourses supporting early childhood policy development (Richardson, 2011). However, this study has grouped these rationales within a broader social investment discourse for understanding the state's interest and responsibility for implementing early childhood services and social policy.

\section{Social Justice Discourse for Early Childhood Policy}

An alternative discourse for understanding policy development to the social investment approach is the social justice approach (Williams, 2010a). This study understands the social justice approach as both a discourse for representing and conceiving of policy development, but also, as a discourse for conceptualizing the state's role in supporting the welfare of citizens that is distinct from the social investment approach. Williams (2010a; 2010b) identifies that unlike the social investment discourse, which is largely set forth by governmental bodies, the social justice discourse has largely emerged from more civil society-oriented claims for the state to meet the care needs of citizens. The social justice frame emphasizes the importance of "equality, empowerment of service users, universal access to financial support and collective services, time to care, independence and autonomy, social rights, quality and choice in care and care recognition" (Williams, 2010a, p. 5). Williams (2010a) states that while claims supporting the social justice frame regarding care policies have survived, they are increasingly threatened by the growing dominance of neo-liberalism since the 1980s. 
Supporting Parents. As was the case with the social investment discourse, the social justice discourse also sets forth an understanding of early childhood services as providing support to parents. Williams (2010a) identifies how a social-justice oriented approach to care policies understands the care of children as an entitlement of parents and children. This approach to supporting parents also seeks to advance gender equality both within families and the labour market, as well as support children and families' welfare (Williams, 2010a). Realizing these aims involves governments, families and both men and women sharing responsibility for the care of children (Williams, 2010). Here, one finds a movement beyond childcare programming supporting parents in general and an attempt to remedy the gender inequality that results from the responsibility for care work falling disproportionately to women. Moreover, unlike the social investment discourse's focus on supporting parents and specifically mothers to work, a more social justiceoriented approach supports limiting individuals' time spent working in order to provide more opportunity to perform care (Williams, 2010a).

Upholding Children's Rights. According to Williams (2010a), the social justice frame supports the rights of children to quality care. Friendly (2006) and Herczog (2012) establish that a number of Articles in the United Nations Convention on the Rights of the Child are connected to ECEC. Harlin and Brown (2006), Friendly (2006), Herczog (2012), Richardson (2011) and Woodhead (2006) highlight the rights-based rationale for early childhood programming. This approach articulates an understanding of children as rights-bearing citizens, whose perspectives and participation should be valued and who have an entitlement to quality care (Friendly, 2006; Richardson, 2011). The children's rights-based approach highlights the importance of early childhood as a unique time- 
period in life (Friendly, 2006) and promotes the protection of children's well-being in the present moment and not just furthering their development (Herczog, 2012). Ultimately, children's rights advance social justice by ensuring the collective protection and realization of all children's care and education needs are met (Williams, 2010a; 2010b).

It is important to note that scholars within the feminist ethics of care have critiqued the rights-based approach for understanding children as future adults as opposed to considering their current lives (Cockburn, 2005). However, Bae (2010) holds that the United Nations Convention on the Rights of the Child sets forth an understanding of children "not as objects to be formed, but as human subjects with their own intentions, interests, relational needs and capacities" (p. 205).

Canada has failed to provide the necessary early childhood policy development in order to fully uphold the rights outlined in the United Nations Convention on the Rights of the Child (Friendly, 2006). Although a children's rights-based rationale for supporting quality early childhood service provision has had limited impact in Canada (Friendly, 2006; Richardson, 2011), it is articulated in the advocacy work of different international organizations and countries (Richardson, 2011).

\section{Social Pedagogical Approach to Early Childhood Programming. In White's} (2011) analysis of international organizations' approach to early childhood policy, she identifies that some organizations draw on a social pedagogical approach. This approach is also common within Nordic, socially democratic governments (Moss, 2006). The social pedagogical approach sets forth a holistic understanding of children's needs and well-being (White, 2011). This approach understands early childhood programming as an entitlement of children and families and not simply a service meant to enable parents to 
work (Moss, 2006). Within the social pedagogical approach, "The pedagogue sets out 'to address the whole child, the child with body, mind, emotions, creativity, history and social identity..." (Moss \& Petrie, 2002, as cited in Moss 2006, p. 159). White (2011) discusses certain international organizations, such as the World Bank, which set forth this holistic understanding of children, which seeks to support "their health and physical development, emotional well-being and social competence, positive attitude toward learning, good communication skills, and cognition and general knowledge" (p. 292).

Unlike the human capital development approach that is set forth within a social investment approach to early childhood policy, the social pedagogical approach does not focus solely on encouraging the development of skills and aptitudes that will advance children's capacity for future productivity and labour market participation. Instead, this approach moves beyond simply emphasizing social and cognitive skills to also encouraging the development of children's physical well-being, their enjoyment of learning and so forth (White, 2011). As a result, the social pedagogical approach can be understood as caring for children as entire beings (Moss 2006) and does not merely support developmental outcomes that will advance personal and collective productivity.

This rationale has been grouped within the social justice approach to early childhood policy as it emphasizes care and education as an entitlement of children and families and seeks to support children's well-being in the present. Williams (2010a) also seems to interpret this approach as aligning with social justice discourse, as demonstrated in her discussion of how this holistic approach to supporting children and parents was reflected in particular policy documents in the United Kingdom during the beginning of the twenty-first century. 


\section{Summary of Literature Review}

This literature review has sought to examine literature regarding the social justice and social investment oriented discursive representations of social citizenship and their underlying rationales for early childhood programming. As previously outlined, the social justice citizenship model emphasizes the importance of the state supporting individuals' welfare in order to protect their rights (Jenson \& Saint-Martin, 2003). This was contrasted to the social investment model of social citizenship, which values participation in the labour market as the best means of supporting citizens' welfare and values social programming that supports labour market participation (Jenson \& Saint-Martin, 2003).

While the social investment model for approaching policy and citizenship has been diversely defined and studied, this paper explores social investment as a discourse for rationalizing early childhood policy expenditure. As such, this review outlined the multiple rationales for early childhood programming that have been set forth within the social investment approach, which include an emphasis on how such programs support children's human capital development and access to equal opportunity, support parents to participate in paid employment and advance collective, economic benefits (Cantillon \& Van Lancker, 2013; Esping-Andersen, 2002; Heckman, 2011; Morgan, 2009).

In addition, the social investment approach to early childhood policy was contrasted to the social justice approach to social citizenship and care-related policies set forth by Williams (2010a; 2010b). Williams (2010a; 2010b) identifies how a social justiceoriented discourse for supporting childcare policies emphasizes support for children's rights to quality early childhood programming and supports fostering a more equal balance for care responsibilities between the government and parents, as well as between 
men and women. This literature review grouped the social pedagogical approach to early childhood care and education within Williams (2010a; 2010b) social justice-oriented framework for understanding care policies, as it emphasizes the need to care for the wellbeing and development of the whole child.

This study seeks to apply and build on the above-mentioned research in order to gain further insight as to how early childhood policy development is conceived in the context of Ontario. Now that the literature regarding the rationales underlying social investment and social justice discourse approaches to early childhood policy development have been established, the focus of the paper will turn to outlining how the researcher undertook content analysis and CDA of Ontario government texts in order to examine the presence of these rationales and discourses in the government's justification of FDK. 


\section{Chapter 4: Methods}

The focus of this chapter is to outline the method used in this research study. As such, this chapter will also provide a detailed outline of how the researcher collected and analyzed twenty-two Ontario government texts in order to establish: what rationales and underlying discourses were used to justify the FDK policy to the public; how prevalent the social investment discourse was in the rationalization of this policy and what discursive mechanisms the texts employed to perpetuate the social investment discourse.

This chapter will begin by describing CDA as the overarching methodological approach that this study has employed. Next, the researcher will establish how this approach is being applied within this study. This discussion will provide an overview of how the researcher collected twenty-two Ontario government texts to be included for analysis. Furthermore, this chapter will offer a detailed account of how the researcher engaged in a two-part analysis of these texts. The first stage of analysis that will be described involves a content analysis of all twenty-two government texts, which seeks to identify the different rationales that the Ontario government employs to justify FDK, as well as the underlying discourses that these rationales reflect. The second stage of analysis that this chapter will describe is a CDA of three texts, which were selected from the previous stage of analysis.

\section{Methods}

In studying the outlined research questions, this study applied CDA as a methodological approach. Fairclough (2010) articulates that while CDA does not have set rules, there are important attributes that should guide research working within this methodological approach. To begin, Fairclough (2010) argues that CDA is not an 
analysis simply of discourse but instead, is "an analysis of dialectical relations between discourses and other objects, elements or moments, as well as analysis of the 'internal relations' of discourse" (p.4). Fairclough (2010) identifies this process of analysis as transdisciplinary, since it "cuts across conventional boundaries between disciplines" (p.4). Fairclough (2003) further articulates that studies employing CDA often incorporate other methods of analysis. The purpose of conducting CDA is ultimately to identify and examine areas of social and political life that should be changed, as well as seeks to promote the change that is deemed necessary (Fairclough, 2010). Through analyzing and critiquing text and its representation of discourse and social processes, the researcher is proposing an additional discourse (Fairclough, 2010).

\section{Data Collection for Content Analysis}

In order to answer this study's research questions, twenty-two textual documents were collected for the first stage of analysis. All of the texts that were included for analysis in this study have been produced by the Ontario government and are publically accessible via the Internet. The texts include: four Speeches from the Throne from the years 2010, 2011, 2013 and 2014; six budget speeches from the years 2010 to 2015; two additional speeches, delivered by the Premier of Ontario, the Honorable Kathleen Wynne; five Progress Reports from 2009 to 2014, as well as four FDK-related policy documents and one Poverty Reduction Strategy from 2014 (Please refer to Appendix A for a list of all of the texts mentioned here).

The texts that have been analyzed in this study are by no means inclusive of all Ontario government texts that have discussed FDK, as this is beyond the scope and purpose of this study. Instead, the researcher has sought to include texts from the years 
2009 to 2015, which reflect different genres and are intended for a range of different sized audiences, as well as different potential stakeholders for FDK. Furthermore, the researcher sought to include texts from the Ontario government in general, as well as from different ministries, such as the Ministry of Education, the Ministry of Finance, which have unique agendas.

In addition to the above justification for selecting the texts, the researcher established additional criteria for including in texts for analysis in this study. Each text was searched to ensure it includes the terms "full-day", "full day", or "all day" in combination with "kindergarten", or "learning".

\section{Approach to Content Analysis}

Fairclough (2003) identifies rationalization as the process of "Legitimization by reference to the utility of institutionalized action, and to the knowledge society has constructed to endow them with cognitive validity" (p. 98). Therefore, in the first stage of analysis, the researcher applied a content analysis of twenty-two Ontario government texts in order to identify what the intended aims of FDK are and in turn, what discourse or discourses do these rationales reflect.

The first stage of analysis began with the researcher thoroughly reading each textual document in order to gain a holistic understanding of the text (Bowen, 2009; Elo \& Kyngäs, 2008; Tesch, 1990). The texts were then re-read, with a focus on identifying and examining aspects of the text that discuss FDK (Bowen, 2009). Next, the researcher sought to determine what aspects of the text could be considered a rationalization for FDK and should therefore be included for analysis. First, the researcher was guided by Fairclough's (2003) articulation of how "semantic relations of purpose... are marked by 
connectors ('so that', 'the purpose of this', 'in order to')"' (p. 98). Thus, the researcher examined the texts for passages where FDK was mentioned in combination with words or phrases such as 'because', 'that is why' and so forth in order to identify examples of the text that established the purpose of the program. Furthermore, passages of the text that establish what the Ontario government is allegedly achieving through implementing this program were also considered indicative of the purpose or rationale for the program and were therefore included for analysis. After selecting only passages of the text that mentioned FDK along with an indication of the purpose or rationale for the program, nineteen texts were included for further analysis.

In order to facilitate the next step of analysis, the researcher transferred selections of all nineteen texts that rationalized FDK into a Microsoft Word document. Next, the researcher conducted open coding through reviewing these selections of the texts multiple times. The researcher wrote notes in the margins of the text using track changes and highlighted the key ideas and concepts that emerged through the texts' description of FDK (Elo \& Kyngäs, 2008; Tesch, 1990). Each rationale or description of the purpose or intent of the FDK program was given a code to capture its content. All codes that emerged from the texts were then included in a separate document, which was examined in further detail (Tesch, 1990). The aim of this process was to establish broader categories of codes (Hsieh \& Shannon, 2005; Tesch, 1990), which reflected each different rationale for FDK that had been identified through analysis.

At the initial stages of the coding process, the researcher grouped rationales into categories reflecting whom FDK claimed to benefit. This resulted in categories such as FDK supports: children; families; the economy and so forth. The researcher then defined 
sub-rationales to reflect the different ways the Ontario government claims that FDK supports these groups. For example, FDK supports families by: saving parents time; saving families and parents money on childcare; supporting parents to balance their work and family life and supporting parents to have a more productive and easier work day. Upon further examination, the researcher realized that the above-mentioned system of categorization lacked analytical clarity and grouped codes together that should instead be considered distinct. For example, at times the text claims to support working parents and at times the text claims to support parents in general, which the researcher determined should be included in separate categories. Thus, the researcher re-organized the codes into categories that better reflected the benefits FDK claimed to advance and for what particular group. Examples of the final overarching categories used to rationalize FDK include: support all children/families; reduce child poverty; and support working parents; support the economy; support the public education system and so forth. Certain overarching rationales for the program were further grouped into sub-rationales (Hsieh \& Shannon, 2005). For example the category of preparing all children for future success was further grouped into: success in life/general; learning; success in formal education and training; labour-market participation; contribution to Ontario and so forth.

Upon finalizing the rationales that had been identified in the text as justifying FDK (Please refer to Appendix B, C and D for a full list of all rationales and sub-rationales, as well as the texts in which they were identified), the researcher carefully examined each rationale in order to establish whether their vocabulary and ideas indicated the presence of social justice, social investment discourse, a combination of both discourses or a different discourse. For this first stage of analysis, the researcher adopted Fairclough's 
(2003) understanding of discourse "as representing some particular part of the world, and... representing it from a particular perspective” (p. 129). Fairclough (2003) states, "We can see a text as drawing upon a discourse even if the realization of that discourse in the text is minimal- perhaps no more than a single word" (p.128). Furthermore, Fairclough (2003) claims that "The most obvious distinguishing features of a discourse are likely to be features of vocabulary - discourses 'word' or 'lexicalize' the world in particular ways" (p. 129). This process of analysis was facilitated by the previously outlined literature review.

For many of the rationales it was fairly clear what discourse they reflected. Other rationales were more challenging to identify with a particular discourse, as they were only vaguely mentioned. In order to facilitate this process, the researcher carefully examined the wording in the texts and relied on the literature review in order to identify what underlying discourse the rationale reflected.

In order to identify the prevalence of the rationales and discourses identified, the researcher recorded the frequency with which codes relating to each rationale and its underlying discourse was identified in the documents. The researcher also organized the rationales and underlying discourses drawn on according to the year the text was produced, as well as according to the genre of the text. This allowed the researcher to examine whether the discourses changed or remained consistent according to their year and genre.

\section{Approach to Enhancing Trustworthiness for Content Analysis}

The researcher undertook multiple efforts in order to enhance the trustworthiness of the findings. First, the researcher discussed the codes with her Supervisor and clarified 
concerns she had regarding coding decisions to enhance the reliability of the analysis.

The researcher has also sought to clearly articulate her process of analysis and to include multiple examples of the content of the findings in order to enhance the trustworthiness

of the findings (Creswell, 2014; Elo \& Kyngäs, 2008). The researcher further sought to provide justification as to why rationales were grouped within different overarching discourses, in order to support their decisions but allow for the possibility for alternative interpretation. Finally, the researcher engaged in reflectivity throughout the research process (Creswell, 2014).

\section{Data Collection for CDA}

For the second stage of analysis, the researcher selected three texts from the previous stage in order to conduct a CDA. These texts include: Open Ontario (Ontario, 2010a), A Question and Answer Guide for Parents (Ontario, 2012a) and Realizing Our Potential: Ontario’s Poverty Reduction Strategy, 2014-2019 (Ontario, 2014c). The selection of these texts was purposeful. First, the researcher chose to select these texts as this study's content analysis indicated these texts provided substantial examples of how the Ontario Government employed social investment discourse in rationalizing FDK. The researcher also selected texts for CDA according to their date. This included selecting one text from the years: 2010, 2012 and 2014. These dates reflect important periods in the implementation of the FDK program, as 2010 was the first year the program was available, 2012 can be considered the mid-period of the dissemination process and 2014 is the year that FDK was intended to be fully available across Ontario. The researcher also chose to select texts from different genres- including a speech, a document specific to FDK and a Progress Report. 
In addition to the above-mentioned purposes for selecting the texts for CDA, the researcher also had a more focused reason for selecting each text. Open Ontario (Ontario, 2010a) was selected for analysis, as this speech is intended for a broad audience and was released during the year that the FDK was first implemented. In addition, A Question and Answer Guide for Parents (Ontario, 2012a) was selected as it is focused specifically on the FDK program and it is seeking to appeal to a particular group of stakeholders to the program. Finally, the document Realizing Our Potential: Ontario's Poverty Reduction Strategy, 2014-2019 (Ontario, 2014c) was included for CDA as Fairclough (2000) identifies how addressing social exclusion is a central focus of third way discourse.

\section{Approach to CDA}

For the second stage of analysis, the research applied Fairclough's (1995) three-part framework for conducting CDA, which involves textual analysis, discourse analysis and analyzing the social and political context in which a problem or phenomenon exists. The aim of this analysis was to establish what textual and discursive practices were employed to support social investment discourse in the Ontario government's rationalization of FDK. CDA has previously been applied to exploring the justification for and representation of early childhood programming policy and advocacy efforts in Canada by Richardson (2011), as well Richardson and Langford (2014).

The first level of CDA that this paper employed was text analysis (Fairclough, 1995). For this analysis, the researcher selected three discursive mechanisms identified by Fairclough $(2000 ; 2003)$ to examine in the texts. The first two discursive mechanisms that this research study examined in the texts are nominalization (Fairclough, 2000; 2003) and listing (Fairclough, 2000). Fairclough (2003) describes nominalization as a "grammatical 
metaphor which represents processes as entities by transforming clauses (including verbs) into a type of noun" (p.220) or "a noun-like entity" (p.13) and often serves to "exclud(e) social agents in the representation of events" (p.220). The second discursive mechanism that this study examined in the texts was the use of listing to structure and present information (Fairclough, 2000). Fairclough (2000) states: “A list is a series of two or more items conjoined together (with or without a conjunction- generally and- marking their connection)" (p. 162). Fairclough (2000) argues that lists establish "equivalences between words and phrases" (p. 161), which serves to "reduce differences" (p. 161). In other words, by using lists to relay information, texts may fail to adequately identify the connection between different statements to the reader (Fairclough, 2000). According to Fairclough (2000), listing information or ideas in a text diverges from a more socially democratic approach. Fairclough (2000) identifies how nominalization and listing were reflected in his analysis of the use of the third way discourse in the political language of the United Kingdom's New Labour Party. Analyzing whether these discursive mechanisms were presented in the texts to support social investment discourse was particularly valuable for the purposes of this paper.

The final discursive mechanism that the researcher examined in the texts was modality (Fairclough, 2003). Fairclough (2003) defines modality as the connection that sentences or clauses establish "between author and representations- what authors commit themselves to in terms of truth or necessity" (p. 219). Fairclough (2003) argues that modality is an important part of establishing identity within a text. Fairclough (2003) describes how modality is identified by the presence of "'modal verbs' ('can, will, may, must, would, should', etc.)" (p. 168), as well "modal adverbs..., participial 
adjectives...(and) mental process clauses..." (p. 170). In examining the texts for the presence of modality, the researcher focused on answering the question: Does the Ontario government commit more strongly to specific rationales for the FDK program and if so, are these rationales reflective of social investment discourse?

The next level of analysis explores the discursive practices within the text (Fairclough 1995). Here, the focus is on analyzing how texts are produced and consumed, although Fairclough's $(1995 ; 2003)$ approach is mostly dedicated to analyzing the production of texts. According to Fairclough (2003), there are three relevant features to analyzing discourses as practices within social life: genre, discourse and style. Fairclough (2003) defines genres of text and speech as "ways of acting" (Fairclough, 2003, p.26) and provides interviewing as an example of a genre. Discourses on the other hand, constitute "ways of representing" (Fairclough, 2003, p.26) the world. Finally, Fairclough (2003) defines styles as "ways of being" (p. 26) and establishing one's identity. This paper analyzed interdiscursivity in the texts, or in other words, "the particular mix of genres, of discourses, and of styles upon which (the texts) dra(w), and of how different genres, discourses or styles are articulated... together in the text(s)" (Fairclough, 2003, p. 218). This study also explored intertextuality in the texts, or "how texts draw upon, incorporate, recontextualize and dialogue with other texts" (Fairclough, 2003, p.17). In doing so, the researcher examined what particular assumptions and ideologies are drawn on in the Ontario government's discussion of FDK (Fairclough, 2003). Furthermore, the researcher not only examined the discourses and additional texts that are incorporated into the textual documents being analyzed, but also sought to establish what fundamental perspectives are absent from the discussion of FDK (Fairclough, 2003). 
Finally, the third level of CDA that was applied within this study involved examining the connection between the discursive practices within the text and the social reality in which they exist (Fairclough, 1995). In this stage of analysis, the researcher sought to identify what social, political and cultural processes and institutions could be influencing the discursive practices identified within the texts (Fairclough, 2010).

\section{Approach to Enhancing Trustworthiness for CDA}

It is necessary to acknowledge what efforts the researcher undertook to enhance the trustworthiness of the findings from this study's CDA. Key critiques of CDA highlight this approach's lack of objectivity in the research process, its largely negative analysis of social phenomenon, as well as its use of "'impressionistic' methodology for analysing text" (Breeze, 2011, p. 520). In order to address these limitations, the researcher has explicitly identified her political position in relation to the research in this study (Breeze, 2011). Furthermore, as recommended by Fairclough (2010) the researcher engaged in reflectivity throughout the research process. In addition, the researcher applied a "disciplined and systematic" (Breeze, 2011, p. 520) approach to analyzing the text of the documents. Finally, the researcher sought to not only identify how discourses that undermine progressive social policy are reflected in the texts, but also sought to highlight discourses that promote social justice in order to propose opportunities for positive change (Breeze, 2011). In the next chapter, this study will provide an in depth description of the findings generated from the content analysis of nineteen Ontario government textual documents in order to demonstrate how FDK was rationalized to the public and what underlying discursive representations of the state's responsibility for citizenship these rationales set forth. 


\section{Chapter 5: Content Analysis Findings}

This chapter will present the findings from a content analysis of the rationales and underlying discourses regarding the welfare state and social citizenship that were employed to legitimize FDK. In doing so, this chapter will answer this study's first, second and third research questions: How is the FDK program rationalized by the Ontario government? How prevalent is the social investment discourse in the Ontario government's rationalization of FDK to the public? What additional discourses have been drawn on in the rationalization of this policy?

An in depth analysis of nineteen Ontario government texts has identified multiple rationales that the Ontario government has employed to legitimize the FDK program to the public. The findings indicate that the Ontario government rationalizes FDK in relation to the social investment discourse by claiming that the program: provides children with opportunities and preparation for future success; supports the economy; builds a stronger workforce; supports working parents; supports children experiencing poverty and supports future generations. FDK is portrayed as an investment in some of the texts, which this study has interpreted as an example of rationalization. Social justice oriented rationales that are reflected in the text include the claims that FDK: supports all families/parents; supports children's present-well being; and supports children's holistic development. In addition to rationales that align with either social investment or social justice discourse, this analysis has identified rationales for FDK that reflect both discourses, which include: supporting parents experiencing poverty; and supporting the public education system. 
In this chapter, each of the above-mentioned rationales will be outlined in detail and will be presented as aligning with social justice discourse, social investment discourse, or at times, bridging both discourses. The aim of this chapter is to demonstrate the prevalence of rationales within each or both discourses and ultimately, to suggest the dominance of the social investment discourse in the Ontario government's rationalization of FDK in the textual documents analyzed in this content analysis.

\section{Social Investment- Oriented Rationales}

Seven of the rationales for FDK identified in this study align with social investment discourse. These rationales include the Ontario government's framing of FDK as a program that: provides children with opportunities to prepare for future success, including future learning, formal education and training, and labour-market integration; builds a strong, competitive workforce; supports the economy; supports working parents; supports children experiencing poverty; supports future generations; and finally, the framing of FDK as an investment.

Providing children with the opportunity for future success. The most prevalent way in which the Ontario government rationalizes FDK in the texts analyzed within this study is as a program to help prepare children for future success. FDK is presented as a program that can provide children with the opportunities and preparation for future success in twelve of the texts analyzed in this study. This rationale encapsulates multiple conceptualizations of the kind of future success that FDK supports children to achieve, including success in their future life in general; success in future learning; success in formal education and training; success in obtaining employment; and success as members of society. The focus of this section will now turn to identifying the sub-rationales that can be grouped under this broader, overarching rationale. 
Eight of the texts refer to FDK as supporting children's future success in general. For example, in the context of discussing FDK and other education initiatives, $A$ Prosperous and Fair Ontario, the Ontario Ministry of Finance (2013) claims, "our government has been making investments in young people ...To ensure they are prepared for both the challenges and opportunities ahead" (p. 13). In Building Ontario Up, Ontario (2014a) states that through FDK, the Ontario government is "ensuring that every child in Ontario has the best possible start in life" (p.3). Although the use of the term 'start' implies a future- orientation, there is no indication as to what particular future the children are being prepared for or in other words, what this start is guiding children towards.

In other texts, the Ontario government provides a slightly more detailed account of FDK's intended aims in preparing children for future success. Three of the texts identify how FDK aims to prepare children for future learning (Please refer to Appendix B). This is demonstrated in The Full-Day Early Learning - Kindergarten Program Draft Version (Ontario Ministry of Education, 2010a), which states, "The purpose of the program is to establish a strong foundation for learning in the early years..." (p. 1). In Ontario's (2014c) Realizing Our Potential: Ontario's Poverty Reduction Strategy, 20142019, "For any child of any background, high-quality early learning can help to identify learning needs at an earlier stage, so they can get the additional support they need to succeed. Early learning also gives us a jump on closing achievement gaps" (p.19). As previously identified, social investment discourse places importance on learning in the early years and throughout life. 
FDK is not only portrayed as supporting students' future learning but similarly, it is also portrayed as supporting children's success in formal education and training. This sub-rationale is presented in eights texts. First, FDK is portrayed as supporting children in transitioning to public school. For example, the Ontario Ministry of Education (2010c) states, "The Full-Day Early Learning Kindergarten Program is vitally important to ensuring that we can significantly increase the number of children who are fully prepared for formal learning and for greater success in life" (p.5). Next, FDK is also portrayed as supporting children's success while in schooling. In the Progress Report 2010, Ontario (2010b) claims that FDK "will give our youngest students a better start to their education" (p. 15). Finally, certain texts go on to claim that FDK will support students' future success in post-secondary education and training. This claim is set forth by the Ontario Ministry of Finance (2011) in Turning the Corner to a Better Tomorrow: "A strong start means our kids are more likely to finish high school and go on to college, university or an apprenticeship" (p.18). Thus, FDK is portrayed as providing students with the foundation for a successful transition into schooling, to achieve academic success during public school, as well as to complete high school and go on to postsecondary education or training programs. This emphasis on academic achievement and training is reflective of the social investment discourse's vision of human capital development as supporting future success and preparing individuals for integration into the market.

In addition to the Ontario government claiming that FDK supports children's future educational success and learning, three texts hold that FDK will support children to access employment in the future. This sub-rationale is articulated in Turning the Corner 
to a Better Tomorrow (Ontario Ministry of Finance, 2011). In describing how FDK will support children, this text states: "A strong start means our kids are more likely to finish high school and go on to college, university or an apprenticeship; more likely to get a good job; and more likely to enjoy a good standard of living and contribute to a stronger Ontario" (Ontario Ministry of Finance, 2011, p.18). In this excerpt, one finds the Ontario government's assertion that success in school is connected to future employment, as well as obtaining a decent living. It is important to highlight how this passage captures the interconnection between the different sub-rationales regarding how FDK supports children's future. Here, FDK is represented as the first stage in a path towards achieving success in formal education and training, ultimately supporting integration into the labour market and constructing the future citizen-worker.

While many of the texts claim that FDK will support children's future success on an individual level, two texts assert that FDK will prepare children to support the province. This sub-rationale for the program is presented in Full- Day Early Learning Kindergarten Program A Reference Guide for Educators for Four-and Five-Year-Olds, which states: “Ontario's children will be getting the strongest possible start in life, and the greatest opportunity to experience success as future contributors to the social, cultural and economic future of our province" (Ontario Ministry of Education, 2010c, p.13). In this sub-rationale, FDK is conceived as a program that prepares students for citizenship in Ontario.

Building a Strong Economy. While the previous rationale for FDK is centered on claiming the program will support children's individual success, the Ontario government also claims that the program will foster more collective, economic benefits. The assertion 
that FDK will contribute to general economic progress is found in four texts. Open Ontario (Ontario, 2010a) offers an example of this rationale, stating that FDK "will build a stronger economy for Ontario. Because to put it simply -- the places with the strongest schools, today, will have the strongest economies tomorrow" (p.6-7). Furthermore, in Building Ontario Up the Ontario Ministry of Finance (2015) articulates the government's aims to distinguish Ontario from "parts of the world (that) rely on lower labour costs as their competitive advantage" (p.10). The text goes on to indicate how this will be achieved:

Our competitive advantage is our talent, our education and our skills.

We know that a well-educated workforce is a competitive workforce.

And that leads to a stronger economy.

It starts at the very beginning...

It is why we raised the wages of child care workers, invested in full-day kindergarten and lowered class sizes (Ontario Ministry of Finance, 2015, p.10). This statement demonstrates the interconnection between supporting children's education and development and the Ontario government's economic aims. The Ontario government's claim that FDK will help foster economic progress is strictly reflective of the social investment discourse, as it reduces the benefits of the program to economic gains. Here, citizens' talent, education and skills are portrayed a mechanism for fostering economic competition, which serves to undermine the intrinsic value of education and learning for human well-being.

Building a Strong Workforce. In addition to claiming that FDK will support Ontario's economic success, the texts further perpetuate an economic-oriented justification for FDK by proposing that the program will contribute to building Ontario's 
future workforce. This rationale for FDK is demonstrated in eight texts. An example of this sub-rationale can be found in the Progress Report 2009 (Ontario, 2009), which states, "Ontario will start phasing in full-day learning for four- and five-year-olds next fall as part of the province's plan to build a well-educated workforce" (p.11). Furthermore, in Open Ontario, Ontario (2010a) states:

Ontarians are some of the most highly skilled and educated workers in the world. And that gives us a competitive edge. It is an edge we must sharpen even further. That's why, starting this fall, full-day learning for four- and five-year-olds will begin at schools across our province (p.6).

Overall, this text emphasizes that FDK can support a human capital development rationale by portraying individuals' education and skills as a means to an economic end. The claim that FDK is part of the Ontario government's plan to build the future workforce is also upheld in A Prosperous and Fair Ontario (Ontario Ministry of Finance, 2013). In this speech, Ontario Ministry of Finance (2013) claims that "Ontario is teaching its young about teamwork and critical thinking ... It is building a workforce that is creative and entrepreneurial. This support starts in full-day kindergarten...”(p. 13). This passage establishes the particular kind of workforce that FDK will support by emphasizing the importance of creativity and entrepreneurship. Furthermore, the use of ellipses connects the claim that students are learning skills such as "teamwork and critical thinking" (Ontario Ministry of Finance, 2013, p. 13) with the following statement regarding building the future workforce. This indicates that perhaps there is a connection between the skills that the program is encouraging children to develop and the skills that are deemed valuable within the future workforce. Ultimately, this rationale reflects the 
social investment discourse's emphasis on supporting human capital development and building a strong, well-educated future workforce.

Supporting Working Parents. In addition to the Ontario government's claim that FDK can prepare children for future success and support a competitive workforce and a strong economy, the Ontario government also claims that the program can support working parents. Four of the texts analyzed in this study outline how FDK seeks to provide parents with assistance in reconciling their work and family responsibilities (Please refer to Appendix B). For example, in Open Ontario, Ontario (2010a) claims that FDK "will help busy parents balance their work and their family lives" (p.6). The texts claiming that FDK will help parents reconcile their family and work responsibilities fail to provide a detailed explanation regarding how this balance will be realized.

Unlike the above texts, which claim FDK seeks to support parents to reconcile their family and work responsibilities, in Turning the Corner to a Better Tomorrow, the Ontario Ministry of Finance (2011) claims that FDK will affect the ease and productivity of parents' work experience. Within this text, FDK is thus framed as more of a program to provide support for parents to work than to support parents to both work and care for their family. Overall, the rationale that FDK supports working parents can be interpreted as aligning with social investment discourse. As previously outlined, the social investment discourse places strong emphasis on ensuring parents' human capital is activated and utilized through participation in the workforce (Morel et al., 2012).

\section{Supporting Children Experiencing Poverty. The program is portrayed as} providing support to children experiencing poverty in two ways: through reducing child poverty and addressing achievement gaps that children may experience as a result of 
socio-economic disadvantage. First, the FDK program is rationalized as part of the Ontario Government's attempt to "lift more children out of poverty" (Ontario, 2010a, p.6; Ontario, 2010b, p.15; Ontario, 2011b, p. 1) in three of the texts analyzed in this study. However, these texts offer no explicit indication as to how FDK will realize this aim. Furthermore, the texts fail to indicate the time frame within which this will be achieved. In addition to claiming FDK will help reduce child poverty, another way in which the program is portrayed as offering support for children experiencing socio-economic disadvantage is through supporting their academic achievement. This sub-rationale is articulated in Ontario's (2014c) Realizing Our Potential: Ontario's Poverty Reduction Strategy, 2014-2019, which claims, "By the time children from low-income families start school, they may already face disadvantages compared to their peers from higher-income families. Enriched education environments, such as the one provided by full-day kindergarten, can help to close that gap" (p. 19). Unlike the Ontario government's previous claim regarding child poverty, the approach outlined in Realizing Our Potential: Ontario's Poverty Reduction Strategy, 2014-2019 (Ontario, 2014c) is focused on clearly identifying how FDK can support children experiencing poverty. As previously outlined, social investment discourse places strong emphasis on supporting children experiencing poverty in order to protect them from facing long-term social exclusion (EspingAndersen, 2002; Heckman, 2011). Therefore, Ontario's (2014c) portrayal of FDK as providing a means of reducing the discrepancy in children's academic performance from different socio-economic backgrounds can be considered indicative of social investment discourse. 
Supporting Future Generations. The framing of FDK as a program that supports future generations is only presented in one text: Progress Report 2014: education (Ontario, 2014b). This rationale is only vaguely mentioned in the text through the statement: "Ontario's 2014 education progress report highlights achievements that are creating opportunities for future generations, such as.... introducing full-day kindergarten" (Ontario, 2014b, p.1). The lack of detail regarding this rationale makes it difficult to align with an overarching discourse. However, as a result of its futureorientation, this rationale can be cautiously interpreted as reflecting social investment discourse.

Investing in Children and Educational Programming. FDK is portrayed as an investment in four of the texts analyzed in this study. Moreover, FDK is portrayed as an investment in two ways: as an investment in people and particularly, children, as well as an investment in educational programming. For example, In A Prosperous and Fair Ontario, Ontario Ministry of Finance (2013) claims, "our government has been making investments in young people ...To ensure they are prepared for both the challenges and opportunities ahead" (p.13). The text then goes on to describe the aims of FDK. The FullDay Early Learning Kindergarten Program A Reference Guide for Educators for Fourand Five-Year-Olds (Ontario Ministry of Education, 2010c) states, "Ontario is investing in the education of its youngest students to better prepare them for future success" (p.1). Here, FDK is conceived as an investment in children's education and not just in children themselves.

The representation of FDK as an investment offers a strong articulation of social investment discourse in the Ontario government's justification of this program to the 
public. Referring to the program as an investment in people is indicative of the human capital development rationale underlying social investment discourse's support for early childhood policy development. While the use of the term investment in reference to programming seems less indicative of social investment discourse, it still implies that educational programs should generate a future-oriented return instead of representing education as a right that supports children's and parents' well-being in the present.

\section{Social Justice-Oriented Rationales}

Three rationales for FDK that emerged through this study's content analysis can be considered oriented towards social justice discourse. The first rationale that aligns with social discourse articulates how FDK provides support to parents and families in general. The second, social justice-oriented rationale for FDK emphasizes how the program supports children's present well-being. Similarly, the third social justice-oriented rationale for the program claims it fosters children's holistic development. These rationales will now be explored in detail, with the aim of establishing how they can be considered distinct from the social investment-oriented rationales.

Supporting all Parents/Families. In addition to claiming that FDK provides support to working parents, FDK is also represented as a program that supports parents and families in general in three texts. FDK is conceived as a parent/family support program by reducing the amount of money that parents have to spend on childcare and through saving parents time. Only one text, Turning the Corner to a Better Tomorrow (Ontario Ministry of Finance, 2011), claims that FDK supports parents to save time. However, this text fails to indicate how FDK provides parents with more time. Three of the documents analyzed in this study indicate how by having their children enrolled in 
FDK, parents can save money that they may otherwise have to spend on early childhood education and care programming (Please refer to Appendix B). For example, the Progress Report 2014: education (Ontario, 2014b) holds that parents can reduce the amount they spend on childcare by approximately $\$ 6,500$ for each child attending FDK.

While the previously identified social investment oriented-rationale for FDK emphasizes how the program can support working parents, the social justice-oriented rationale identifies how FDK supports all parents and not simply working parents. Thus, FDK moves from supporting labour-market participation to a policy that provides universal benefits to parents and their families by reducing the cost of childcare for all families whose children attend FDK. This rationale can be interpreted as falling within social justice discourse, as it supports the social pedagogical approach's emphasis on providing early childhood services as a universal benefit and support for all families (Moss, 2006). In addition, this rationale reflects the social justice frame's emphasis on the state sharing some of the responsibility for and financial cost of children's care with families (Williams, 2010a). Furthermore, this rationale seeks to support all families, and not simply working families.

Supporting Children's Present Well-Being. Three of the texts analyzed in this study rationalized the program as providing support for children's well-being in the present context. For example, in The Full-Day Early Learning - Kindergarten Program Draft Version (Ontario Ministry of Education, 2010a), one of the stated goals of the program is "to provide a play-based learning environment" (p. 1). This goal is not futureoriented and instead, focuses on supporting children's present well-being and learning. This text also provides another example of how the FDK program is portrayed as 
supporting children in the present, stating, "The Full-Day Early Learning-Kindergarten program provides children with a wide range of opportunities to learn, practise, and demonstrate knowledge and skills in all areas of learning" (Ontario Ministry of Education, 2010a, p.3). Unlike previous examples indicated in the social investment discourse where the intent of the program was connected to supporting children's future opportunities for learning and success, in this statement, the focus is more strictly oriented towards the present. Another example of this rationale is demonstrated in The Full-Day Early Learning- Kindergarten Program The Extended Day Program Draft Version (Ontario Ministry of Education, 2010b). This document describes the extendedday component of FDK programming and states, "The extended day program is complementary to the core program and aligned with it in order to provide a seamless and consistent experience for the children" (Ontario Ministry of Education, 2010b, p.1). Furthermore Full-Day Early Learning-Kindergarten Program for Four-and Five-YearOlds - A Reference Guide for Educators claims the FDK program aims to: provide a balance of investigation or exploration and guided explicit instruction through play-based learning. Children need many opportunities to investigate and explore. These experiences allow children to build on their existing knowledge, create and clarify their own new understandings, and experience a variety of approaches to a problem or question (Ontario Ministry of Education, 2010c, p. 6). Supporting Children's Holistic Development. Four of the texts analyzed in this study present a social pedagogical rationale for FDK. This rationale is articulated through portraying the program as supporting children's holistic development. The Full-Day Early Learning- Kindergarten Program The Extended Day Program Draft Version 
(Ontario Ministry of Education, 2010b) text describes how early childhood educators will implement "developmentally appropriate, and culturally responsive program planning, to facilitate experiences that promote each child's physical, cognitive, language, emotional, social, and creative development and well-being" (p. 1). Within this frame, emphasis is placed on FDK supporting children's present well-being and development and not just fostering skills that are linked to future personal and economic success. This rationale can be understood as promoting social justice, as it emphasizes state responsibility for caring for and meeting the needs of the whole child and not simply serving future productionoriented ends.

\section{Social Investment and Social Justice- Oriented Rationales}

While the above-mentioned rationales align with either a social investmentoriented or social justice-oriented discourse, two rationales in this study reflect aspects of both discourses. These rationales include the claim FDK supports parents experiencing poverty and the claim that FDK builds a stronger public education system.

Supporting Parents Experiencing Poverty. In addition to the previously established child-focused, poverty-alleviation rationale, one text claims that FDK provides support for parents experiencing poverty. The Realizing Our Potential: Ontario's Poverty Reduction Strategy, 2014-2019 (Ontario, 2014c) provides the only reference to how FDK will support parents experiencing poverty. This document states, "Full-day kindergarten also helps parents living in poverty by providing more time in the day to pursue education, training or employment while reducing child care costs by approximately $\$ 6,500$ per year" (Ontario, 2014c, p.19). The Ontario government's claim that FDK supports parents experiencing poverty reflects both social justice discourse and 
social investment discourse. First, this rationale incorporates social justice discourse as it identifies the financial support that parents can access in the present through having their children enrolled in FDK. However, this rationale also reflects social investment discourse as it focuses on supporting parents experiencing poverty by providing them with the opportunity to engage in human capital development or to enter the workforce.

Supporting the Public Education System. A final and more institutional, systemic aim for FDK is that the program supports the broader, public education system. This rationale is established in five texts (Please refer to Appendix B). An example of this rationale is found in A Question and Answer Guide for Parents (Ontario, 2012a), which claims that FDK "is part of Ontario's plan to build a stronger school system" (p.1). In addition to claiming that FDK supports the public education system in general, The Way Forward (Ontario, 2013b) describes FDK as a part of the Ontario government's plan to establish a "comprehensive early learning and care system" (p.8). In both texts, supporting public education is represented as an end in of itself and can be arguably understood as a public good. This rationale aligns with social justice discourse by emphasizing collective responsibility for the care and education of children.

Unlike the previous examples, the Premier's Remarks at the London Chamber of Commerce (Ontario, 2013a) connects support for public education through the FDK program to economic ends. This is demonstrated in the following passage: "I want to build our economy around people like you. And our government understands that for this to happen, we have to focus our investments on giving people the right skills, support and resources. That's why we're investing in education and training” (Ontario, 2013a, p.1). The document goes on to state, "We are focused on building our world class education 
system, through our commitment to full day kindergarten..." (Ontario, 2013a, p.1).

Although the statement that mentions FDK connects the program to supporting the education system, the broader context of the passage demonstrates the underlying economic rationale. Unlike the other examples, which align with a social justice discursive approach, in this text education is merely a mechanism for achieving a larger, economic end.

\section{Changes in Discursive Representation of FDK According to Genre and Year}

The final stage of this study's content analysis sought to examine how the representation of FDK changed according to the year the textual documents were produced, as well as their genre (Please refer to Appendix F and Appendix G). However, due to the lack of a similar number of texts representing each year and genre that were identified as rationalizing FDK, the findings from this analysis were inconclusive.

\section{Summary of Findings: Content Analysis}

The findings from this study's content analysis of nineteen Ontario government texts, has identified twelve rationales that the Ontario government has set forth in order to rationalize FDK to the public. These rationales include presenting FDK as a program that: provides children with opportunities and preparation for future success; supports economic progress; builds a stronger workforce; supports parents to work; supports children experiencing poverty; supports future generations; supports all families/parents to save time and money; supports children's present-well being; supports children's holistic development; supports parents experiencing poverty to pursue human capital development and employment; and finally, strengthens the public education system. 
The findings from this study's content analysis indicate that rationales reflecting social investment were drawn on more frequently in the texts than rationales reflecting social justice discourse (Please refer to Appendix E). Seven rationales identified in the texts were reflective of social investment discourse, while three rationales were reflective of social justice discourse and two rationales were reflective of both discourses. An unexpected outcome from the above-mentioned findings was the prevalence of rationales in the text that can be interpreted as aligning with both social investment and social justice discourses (Please refer to Appendix D). The implications of these findings will soon be outlined in extensive detail in the discussion chapter. However, the next section of this paper will turn to describing the findings from this study's CDA. 


\section{Chapter 6: CDA Findings}

This chapter will present the findings from a CDA of three textual documents that were previously examined in this study's content analysis. These texts include: the 2010 speech from the throne, Open Ontario (Ontario, 2010a); A Question and Answer Guide for Parents (Ontario, 2012a); and Realizing Our Potential: Ontario's Poverty Reduction Strategy, 2014-2019 (Ontario, 2014c), which will be referred to as Poverty Reduction Strategy. This CDA has sought to answer: What discursive mechanisms and practices has the Ontario government employed to support social investment discourse in justifying FDK to the public?

This chapter will begin by briefly outlining the purpose of each text as a whole in order to facilitate a more in depth CDA of the texts' justification of FDK. The remainder of the chapter will focus on outlining the findings from this study's CDA. This chapter will establish whether nominalization, listing, modality, intertextuality, interdiscursivity and the reiteration of key assumptions identified by Fairclough (2000) were used to support the social investment discursive representation of FDK. Finally, this chapter will seek to draw potential connections between the discursive representation of FDK and the broader social, economic and political context within which this policy emerged.

\section{Summary of Texts Included in CDA}

Before examining the findings from this study's CDA, a brief description of each text included within this analysis will be established. The first text that was included for CDA was the 2010 Speech from the Throne, which was titled: Open Ontario (Ontario, 2010a). In Canadian provinces, the Lieutenant Governor delivers Speeches from the Throne when a legislative session commences. Honorable David C. Onley delivered the 
speech on March $8^{\text {th }} 2010$, which outlined the Ontario government's plans for the upcoming session. The researcher conducted a CDA of the section of this speech that justifies FDK (Please refer to Appendix H).

The next text that was examined in this study's CDA was A Question and Answer Guide for Parents (Ontario, 2012a). This text was published two years after the Ontario government began the process of implementing the program throughout the province. Most of this document focuses on explaining FDK to parents with children in the program through providing answers to anticipated questions that parents might have. One section of the document is specifically dedicated to justifying why the Ontario government has implemented FDK. The researcher has included this passage for CDA in order to examine whether particular discursive mechanisms are used to perpetuate social investment discourse (Please refer to Appendix H).

The final text included for CDA was the Poverty Reduction Strategy (Ontario, 2014c). This text was produced at the end of FDK's implementation and outlines the Ontario government's plan to provide targeted support to a greater number of populations experiencing vulnerability and socio-economic disadvantage. The Poverty Reduction Strategy (Ontario, 2014c) emphasizes the importance of supporting individuals to achieve their full potential. A CDA was conducted of the section of the Poverty Reduction Strategy (Ontario, 2014c) that rationalizes FDK (Please refer to Appendix H).

\section{Text Analysis}

The first stage of CDA that this study conducted was a close, textual analysis of the documents. The researcher analyzed whether nominalization, modality and listing were used to perpetuate social investment discourse. As will soon be outlined in extensive 
detail, nominalization and modality were employed by the Ontario government in all three texts in order to perpetuate the social investment discursive representation of FDK. However, the Ontario government did not use listing to support social investment discourse in the texts' rationalization for FDK.

Nominalization. The first discursive mechanism that the researcher examined in the texts was nominalization. Nominalization is presented in all three texts through the use of the term 'start' as a noun as opposed to a verb in relation to rationalizing FDK. For example, in Open Ontario (Ontario, 2010a) nominalization is demonstrated in the following statement, referring to FDK: "It's part of a plan to help more children get a strong start in school -- so they can go on to college, university or training programs -and find a great job" (p.6). A Question and Answer Guide for Parents (Ontario, 2012a) sets forth a similar example of nominalization. This text states, "Full-day kindergarten is designed to give your child a stronger start in school and in life" (Ontario, 2012a, p.1). Like the other texts, the Poverty Reduction Strategy (Ontario, 2014c) also nominalizes 'start' by stating: "The program is giving children a stronger start in life through early learning programs" (p. 19).

In nominalizing the term 'start' in relation to FDK, the above statements make it unclear what subjects are completing the central action. The texts seem to imply that it is only the Ontario government conducting the action in the statements, as it is taking responsibility for children's future and providing them with an opportunity for success through the FDK program. In this sense, the nominalization of 'start' works to construct a grammatical metaphor for equality of opportunity. However, upon closer examination of the statements, one can determine that it is children who will really be performing the act 
of starting their future or preparing for it. Although the texts imply that it is the government acting to take responsibility for the future success of children, in actuality, the responsibility for children's future lies with the children themselves. As a result, the texts' use of nominalization can be interpreted as subtly advancing social investment discourse's emphasis on supporting individuals' responsibility for their own welfare.

Modality. The next discursive mechanism that the researcher examined in the texts was the influence of modality in establishing the Ontario government's commitment to the intended aims of FDK. This discursive mechanism was demonstrated in all three of the texts in support of the social investment discourse.

Open Ontario (Ontario, 2010a) demonstrates a strong commitment to social investment-oriented rationales for FDK. All of the rationales for FDK in this text have been identified as aligning with social investment discourse. These rationales are presented as irrealis or predictive statements about what the program will allegedly achieve (Fairclough, 2003). This text states that FDK is intended to prepare children for future success (Ontario, 2010a). This statement is modalized through the text's use of "part of a plan to" (Ontario, 2010a, p. 6), which functions as a hedge (Hodge \& Kress, 1988, as cited in Fairclough, 2003). Ontario’s (2010a) modalization of this statement reduces its strength of commitment to this claim. Unlike the passage's first statement, the next three intended outcomes of FDK, which include reducing child poverty, supporting working parents and fostering economic success, are prefaced with the use of the modal verb 'will'. This indicates Ontario's (2010a) strong commitment to these program aims.

The next text that was examined for modality was A Question and Answer Guide for Parents (Ontario, 2012a). This text demonstrates a moderate commitment to social 
investment-oriented rationales for FDK, as well as a social justice-oriented rationale. This text sets forth a social investment-oriented rationale that the program "is designed to give your child a stronger start in school and in life (Ontario, 2012a, p.1). This statement can be read as a categorical assertion, which indicates the Ontario government's strong commitment to this rationale. However, this passage's use of "is designed to" (Ontario, 2012a, p.1) to preface this rationale implies that the program has been constructed to achieve this outcome but that there is no guarantee that this effect will be realized. This text also hedges rationales for FDK by claiming that it is "part of Ontario's plan to support early learning and child development, build a stronger school system and contribute to Ontario's long-term economic competitive advantage" (Ontario, 2012b, p. 1). Overall, Ontario's (2012a) use of modality in representing FDK seems to support the social investment discourse's representation of the program but not as strongly as in Open Ontario (Ontario, 2010a). The text's use of modality also demonstrates a commitment to the social justice-oriented rationale that FDK supports public education.

The Poverty Reduction Strategy (Ontario, 2014c) also perpetuates social investment discourse, as well as a combination of social investment and social justice discourse through modality. In this document, Ontario (2014c) claims that FDK "is giving children a stronger start in life through early learning programs" (p. 19). Another strong assertion that Ontario (2014c) sets forth is that the program "helps parents living in poverty" (p.19). These statements can be understood as categorical assertions, as they "leave no room for other possibilities" (Fairclough, 2003, p. 46) and thus, demonstrate Ontario's (2014c) strong commitment to these intended program outcomes.

Unlike the claims that FDK will support children's opportunity to achieve future 
success and support parents experiencing poverty, another intended outcome of the program is not stated quite as assertively. This is demonstrated with Ontario's (2014c) claim that "Enriched education environments, such as the one provided by full-day kindergarten, can help to close that gap" (Ontario, 2014c, p. 19). This statement is modalized through the use of the modal verb 'can'. Here, the text is not claiming that FDK will reduce achievement gaps, but rather, that it can do this.

Listing. The final discursive mechanism the researcher examined in this study's textual analysis was the texts' use of listing to justify FDK. Listing was demonstrated in the rationalization for FDK presented in A Question and Answer Guide for Parents (Ontario, 2012a) and the Poverty Reduction Strategy (Ontario, 2014c). However, the examples of listing in these texts do not support social investment discourse.

\section{Discourse Analysis}

After this study's textual analysis, the focus shifted to analyzing the texts at the level of discourse. This study's discourse analysis examined whether the texts supported a social investment-oriented representation of FDK through interdiscurisivity and intertextuality. For Fairclough (2003), interdiscursivity and intertextuality are closely related concepts. Fairclough (2003) articulates that an analysis of interdiscursivity examines the way in which different discourses, genres and styles are combined and related to one another in a text. In a slightly different vein, Fairclough (2003) defines intertextuality as the way in which a text establishes a connection to other texts or integrates aspects of other texts into its content.

Interdiscursivity. Turning now to the presence of interdiscursivity in the texts, in Open Ontario (2010a), all five of the rationales presented for FDK are reflective of a social investment discourse. What is particularly important in this text is not simply the 
prevalence of social investment-oriented rationales but also the language that the Ontario government employs to prioritize the economic rationale for FDK. This is captured in the following passage referring to FDK: "It will build a stronger economy for Ontario. Because to put it simply -- the places with the strongest schools, today, will have the strongest economies tomorrow" (Ontario, 2010a, p.6-7). The assumption set forth in this passage is that education is essential to supporting economic competition and strength. By solely focusing on the economic rationale for FDK, Open Ontario (Ontario, 2010a) fails to offer an understanding of education as a right and an end in of itself and undermines the possibility of advancing a social justice-oriented representation of FDK. Unlike Open Ontario (Ontario, 2010a), A Question and Answer Guide for Parents (Ontario, 2012a) sets forth social justice and social investment-oriented discursive representations of the program. A Question and Answer Guide for Parents (Ontario, 2012a) offers three social investment-oriented rationales by claiming that FDK will help prepare children for future success, support children's learning and development and support Ontario's economy, which reflects social investment discourse. Ontario (2012a) also provides one social justice-oriented rationale for FDK in by claiming that the program supports the public education system, which reflects social justice discourse.

Two of three rationales for FDK identified in the Poverty Reduction Strategy (Ontario, 2014c) reflect social investment discourse. This text claims that FDK supports all children by providing them with "a stronger start in life" (Ontario, 2014c, p.19) and can provide more specific support for children experiencing socio-economic disadvantage in order to ensure they do not fall behind their peers. These rationales reflect social investment discourse's concern with the impact that disadvantages early in life can have 
on individuals' long-term welfare and opportunities for success (Esping-Andersen, 2002; Heckman, 2011). Moreover, The Poverty Reduction Strategy (Ontario, 2014c) claims that the program supports parents experiencing poverty by freeing up time for human capital development and or labor market integration. Here, Ontario (2014c) seems to assume that parents are experiencing poverty due to a lack of education or employment, which neglects the possibility that parents may be employed but not receiving a wage above the poverty line, or that they may have extensive education but are unable to secure employment. Ontario (2014c) seems to assume that poverty is an individual problem instead of acknowledging its connection to systemic barriers.

Ontario (2014c) also claims FDK supports parents experiencing poverty by decreasing childcare costs. This reflects a social justice-oriented rationalization of the program, as the government is sharing some of the cost for childcare with families and is providing immediate support for all parents, particularly those facing socio-economic disadvantage.

Another way in which the Ontario's government's use of interdiscursivity advances a social investment-oriented representation of FDK is through the establishment of the program's identity and in turn, the government's identity. For example, Ontario (2010a) claims, "Ontarians are some of the most highly skilled and educated workers in the world. And that gives us a competitive edge. It is an edge we must sharpen even further" (p.6). This economic rationale for FDK reflects third way discourse's assumption that the global economy is defined by competition and that the government should implement policies that support competitiveness within this system (Fairclough, 2000). 
Another assumption underlying third way discourse, as identified by Fairclough (2000), is that the same policies that foster economic growth in the new, knowledgebased economy are also effective in enhancing social inclusion and fairness (Fairclough, 2000). Fairclough's (2000) analysis of the New Labour Party's application of third way discourse indicated that education initiatives constitute a central policy domain in which this dual objective can be realized. This study proposes that the above assumption is perpetuated through Ontario's (2010a) claim that FDK helps reduce child poverty and advances economic growth. Through this assertion, the Ontario government constructs its identity as supporting social inclusion and economic prosperity.

The Ontario government also reinforced a social investment-oriented rationalization of FDK through its representation of citizens' voices and interests. Open Ontario (Ontario, 2010a) claims that FDK will provide all children with the opportunity for future success in education and labour market integration and will support children experiencing socio-economic disadvantage. This representation of children as vulnerable beings or future citizen-workers fails to offer a holistic vision of how FDK can support children as citizens in the present. Ontario (2010a) further perpetuates social investment discourse by claiming that FDK "will help busy parents balance their work and their family lives" (p.6). Here, the voices and interests of parents who are unemployed or engaging in unpaid care work are silenced. Ontario's (2010a) emphasis on supporting present and future workers undermines the possibility of a social justice-oriented representation of FDK, which could highlight the benefits of the program for all parents and children.

A final way in which interdiscursivity was identified in this study's analysis was through Ontario's (2012a) combination of different genres in A Question and Answer 
Guide for Parents. This text seems to present an interview-like, dialogue-oriented genre, whereby the government responds to alleged questions parents may have regarding FDK. However, through the text's title and structure, one gains the impression of a guide or user manual. The actual voices of parents are also not explicitly presented in the text. Instead of engaging parents in meaningful dialogue regarding their concerns related to FDK, it seems that Ontario (2012a) is trying to sell FDK to parents and guide them to participate in the program in a way that will realize its pre-established aims. While at first this text seems to be oriented towards communicative action and political deliberation, it is also managerial and oriented towards strategic action (Fairclough, 2000).

Intertextuality. All three texts analyzed in this study's CDA failed to incorporate intertextuality in relation to justifying FDK. Beginning with A Question and Answer Guide for Parents (Ontario 2012a), this document is organized around highlighting anticipated questions that parents may have regarding FDK and providing answers to these questions. The use of questions and answers to structure this document can be interpreted as implying that the Ontario government is acknowledging the voices of parents and engaging in a form of dialogue through responding to questions that parents might have regarding the program. However, as it is the Ontario (2012a) that establishes and answers the questions in the text, one could also argue that it is only truly the government's voice that is represented in this text and that this document ultimately fails to meaningfully incorporate parents' questions and concerns.

Both the Poverty Reduction Strategy (Ontario, 2014c) and Open Ontario (Ontario, 2010a) provide rationales for FDK that may be linked to other texts but fail to provide any explicit reference to such texts. A possible example of intertexutality is demonstrated 
in Ontario's (2014c) statement: "For any child of any background, high-quality early learning can help to identify learning needs at an earlier stage, so they can get the additional support they need to succeed" (p. 19). Similarly, Ontario (2010a) states, "to put it simply -- the places with the strongest schools, today, will have the strongest economies tomorrow" (p. 6-7). Without explicitly linking the above social investmentoriented rationales to other texts or sources, both examples constitute assumptions and therefore, do not reflect intertextuality.

Governments have a unique capacity to make bold claims, as reflected in the assumptions supporting social investment discourse outlined above (Fairclough, 2003). By failing to ground the assumptions that reinforce a social investment-oriented representation of FDK with evidence, the Ontario government is not supporting individuals to question these claims. In other words, these ideas are constructed as the only way of understanding FDK and its impact on children and families, which limits the opportunity to envision different possibilities for the program and even contributes to hegemony. As Fairclough (2003) highlights, "Seeking hegemony is a matter of seeking to universalize particular meanings in the service of achieving and maintaining dominance, and this is ideological work" (p.58). Fairclough (2003) further states, "texts can be seen as doing ideological work in assuming, taking as an unquestioned and unavoidable reality" (p.58) that a phenomenon exists in a particular way. Therefore, the Ontario government's use of assumptions to reinforce a social investment-oriented representation of FDK can be interpreted as having ideological outcomes. 


\section{Social and Political Context}

In $\mathrm{CDA}$, it is important to not only examine how social investment discourse has been supported in the Ontario government speeches and documents through textual and discursive practices, but also to analyze the broader context in which this program emerged and the implications this may hold for this study's findings. Therefore, this section will seek to connect the dominance of social investment discourse in the Ontario government's rationalization for FDK with the social, political, economic and institutional processes taking place before and during the implementation of this program.

FDK was introduced during the global economic downturn and a period of fiscal deficit in Ontario. According to Turgeon (2014), framing government expenditure on early childhood services as an investment to support children and not as a program for the family may garner more positive feedback from the public or particular politicians. Due to the political and economic context in which FDK was implemented, it is possible that the social investment discourse represented an appealing rationale for the Ontario government to employ in order to justify this policy initiative.

Nolan (2013) discusses social investment as a political discourse, which must appeal to important stakeholders in policy development. In particular, social investment discourse needs to persuade the more traditional economic camp to believe "that social spending is or can be a productive factor" (p. 466). As previously established in this study's chapter outlining the historical background of FDK's emergence in Ontario, the Conservative Party has opposed this policy initiative as a result of concerns over its cost and the need to address the province's fiscal deficit (Turgeon, 2014). It could be suggested that the Conservative Party's opposition to FDK due to budgeting concerns 
compounded with the pressures of the global economic downturn may have contributed to the dominance of the social investment discourse in justifying this policy to the public.

While economic pressures and opposition from the Conservative party are significant to the context in which this policy emerged, it is also important to examine the potential internal political party influences that could have shaped the Ontario Liberal government's discursive representation of FDK. This analysis can be supported by reflecting on the dominance of social investment discourse in previous early childhood policy advocacy within the federal Liberal party. Richardson's (2011) analysis of how early childhood programming was discussed during Canada's federal election in 2006 found that the Liberal Party employed a human capital development discourse to support government expenditure on early childhood programming. The present study has grouped human capital development discourse within the broader framework of social investment discourse. Furthermore, Dobrowolsky and Saint-Martin (2005) outline how the federal Liberal party during former Prime Minister Jean Chrétien’s Liberal government employed social investment discourse, particularly in relation to early childhood services. Therefore, it could be suggested that the Ontario Liberal government's employment of social investment discourse may reflect an attempt to maintain the Liberal Party's consistent framing of early childhood policy at the provincial and national level.

In addition to national, political influences that could be connected to the dominance of social investment in the Ontario government's approach to framing FDK, it is also important to acknowledge the potential role of international organizations. As previously established, the OECD's approach to early childhood programming influenced the former Liberal Premier of Ontario, Dalton McGuinty, to implement FDK (Turgeon, 
2014). Mahon (2010) has identified how the OECD has supported the social investment approach to justifying childhood policy development. Thus, it is possible that the dominance of social investment discourse in the Ontario government's rationalization of FDK is related to the OECD's influence in developing this policy.

This final section of this study's CDA has explored the broader context within which FDK emerged. The intention of this analysis was not to establish definitive conclusions. Instead, the purpose was to offer suggestions regarding the social, political, economic and institutional practices that may have contributed to the dominance of social investment in the Ontario government's discursive representation of FDK.

\section{Summary of Findings: CDA}

This study's findings from an in depth CDA of three textual documents produced by the Ontario government indicated how particular textual and discursive practices were advanced to support social investment discourse in the justification of FDK in Ontario. This study found that the Ontario government employed nominalization, modality and interdiscursivity to support a social investment-oriented representation of FDK. However, this study did not find that listing and intertextuality were significant rhetorical strategies used to advance social investment discourse in the texts and therefore, these discursive mechanisms will not be discussed in further detail.

First, all three texts included for CDA indicated the presence of nominalization through the use of the term 'start' in reference to the program. Through identifying the FDK program as the Ontario government's approach to offering children a positive 'start', the texts indicate that the government is taking responsibility for children to 
access equal opportunity for the future, while masking the underlying emphasis that is placed on individual responsibility.

In addition to the Ontario government reinforcing social investment discourse through nominalization, this study's analysis indicated that modality further supported the dominance of social investment's representation of the FDK program. Overall, the Ontario government demonstrates a strong commitment to claims that FDK will foster outcomes that reflect social investment-oriented goals through the use of modal verbs and categorical assertions. Not only does the Ontario government's strong commitment to the program's social investment-oriented aims further enhance this discursive representation of the program, it also fails to acknowledge the potential for different perspectives regarding the aims of the program or the possibility that the program may not realize these intended outcomes.

Social investment discourse was the dominant representation of FDK in all three of the texts explored through this study's CDA, although to varying degrees. The greater representation of rationales that align with social investment discourse undermines the representation of a more social-justice oriented discursive representation of the FDK program. In other words, the Ontario government has intentionally prioritized social investment-oriented rationales for FDK through incorporating these rationales much more frequently in the texts and using language to reinforce the importance of these rationales. It can therefore be argued that in the Ontario government's discursive representation of FDK, it is establishing an identity as a government that places greater emphasis on social investment-oriented goals than social justice goals. 
This chapter has sought to examine how the Ontario government's use of text and discourse practices has reinforced the social investment discourse as the dominant representation of FDK in these texts. Now that the findings from this study's content analysis and CDA have been outlined, the focus of the next chapter will turn to examining the implications of these findings for early childhood policy development. 


\section{Chapter 7: Discussion}

The aim of this chapter is to highlight and discuss key findings from both this study's content analysis and CDA of the Ontario government's rationalization of FDK to the public in textual documents. This chapter will focus on the most fundamental insights gleaned from this study's content analysis and CDA.

This chapter will begin by comparing the different rationales and underlying discourses for FDK identified in this study's content analysis with findings from previous literature regarding the justifications for early childhood policy. An in depth examination of key findings will then build connections between both this study's content analysis and critical discourse analysis in order to reflect on the potential limitations of particular social investment-oriented rationales. Furthermore, this chapter aims to explore the possibilities that are presented with particular social-justice oriented rationales and rationales that combine both discourses in relation to envisioning early childhood policy.

\section{Comparison of Findings to Previous Literature}

Many of the rationales set forth for FDK in the Ontario government texts analyzed in this study's content analysis have been identified as key rationales for early childhood programming in previous literature. The different rationales for early childhood policy that have been highlighted by Friendly et al. (2006) and Langford et al. (2013) have also been articulated by the Ontario government in support of FDK in the texts analyzed in this study. It is important to note that additional rationales that were not identified in previous literature were also set forth in the justification for FDK, such as the claim that this program strengthens the public education system and supports future generations. The findings from this study regarding the dominance of social investment discourse are consistent with previous literature indicating the influence of this discourse in supporting 
early childhood policy development at the national and provincial level (Bundy, 2012;

Dobrowolsky \& Saint-Martin, 2005). This study’s findings not only reflect previous

literature regarding rationales and discursive representations of early childhood services

in Canada, but also reflect findings from international research (White, 2011).

\section{Discussion of Key Findings}

The focus of this discussion will now turn to a more in depth examination of significant findings this analysis has set forth. The first of these findings that will be explored in detail is the influence of a human capital development approach underlying multiple rationales for FDK identified within this study. Then, this section will examine the Ontario government's reference to the FDK program as an investment. In addition, the discussion will explore the particular vision for advancing equal opportunities for all children and supporting children from disadvantaged backgrounds that is set forth through the social investment discursive representation of FDK and the discursive mechanism of nominalization. In doing so, this discussion will shed light on the benefits and limitations that these findings hold for supporting just outcomes for all children and families.

After examining the above findings regarding the dominance of the social investment rationale, the focus will turn to exploring the potential benefits offered by the social justice rationale's emphasis on a social pedagogical approach to early childhood programming, which was identified in the texts. In addition, this section will also briefly address the absence of a human rights-oriented rationale for FDK and the importance of incorporating this rationale within the framing of state expenditure on early childhood programming. 
Finally, this section will explore the rationales that bridged both social justice and social investment discourse. This discussion will highlight the potential possibilities for reconciling social investment and social justice within a broader framework for justifying public expenditure on early childhood programming and services

The Limitations of Human Capital Development. Multiple social investmentoriented rationales for FDK reflect an emphasis on the value of the program in advancing children's human capital development. First, the rationale that FDK provides children with opportunities and preparation in order to be successful in learning and formal education, to go on to post-secondary education and training and to eventually obtain employment and contribute to their society is representative of an underlying focus on human capital development. Here, the Ontario government's focus is on how FDK can support children to develop the necessary skills and education in order to be productive, future citizens. Another way in which the human capital development frame for the program is demonstrated is through the claim that FDK will help build the future workforce. Furthermore, the economic rationale for FDK also draws on human capital development framing, as the implication within this rationale is that children will grow up to be productive citizen-workers, who will contribute to Ontario's economic advancement.

This study's CDA indicated that the Ontario government's representation of FDK as supporting particular citizens' interests reinforces social investment discourse's emphasis on human capital development. This is particularly demonstrated in Open Ontario (Ontario, 2010a), through its emphasis on the ways in which FDK supports children to achieve academic success and gain employment, as well as supports parents to 
work. As previously established, Ontario's (2010a) portrayal of FDK as a support for children as future-citizen workers and parents as present workers can be interpreted as advancing the social investment conceptualization of citizenship and social welfare programming as focused on human capital development and labour market integration (Jenson \& Saint-Martin, 2003). This conceptualization undermines a more social-justice oriented representation of citizens in the present context, as set forth by Moss (2006) for example, whereby children and families are seen as entitled to support and early childhood services.

White (2011) provides valuable insight regarding the limitations of human capital development rationales in recognizing the fundamental value of early childhood programming. On the one hand, White (2011) argues, "A focus on human capital development arguments can be tremendously beneficial in creating the normative and policy rationales for government investment..." (p.300). On the other hand, there are significant limitations and potential negative consequences of the human capital development approach to framing early childhood programs. White (2011) highlights the concern that a focus on human capital development in early childhood programming can undermine the fundamental importance of caring, which represents the customary rationale for these programs. White (2011) further argues that "Seeing these programs and services as solely instrumental in leading to individual success in life devalues the concept of care as valuable in itself...” (p. 300).

Furthermore, Woodhead (2006) identifies "ethical objections" (p.16) to a human capital approach. According to Woodhead (2006), these objections are centered on the human capital development approach's "instrumental view of the young child as a natural 
resource to be exploited" (p.16). Both Woodhead (2006) and White (2011) indicate that the human capital development approach's emphasis on molding individuals for future success fails to adequately address the underlying systemic and structural change that will support individual well-being and development. It is therefore important to consider the limitations of the human capital development discourse underlying many of the rationales set forth by the Ontario government in support of FDK. Ultimately, the work of White (2011) and Woodhead (2006) seems to suggest that this discourse needs to be balanced with an emphasis on how early childhood policy can both support individual development and foster broader, systemic support for children and families.

Emphasis on Supporting Equality and Opportunity. A potentially positive outcome of the social investment discursive representation of FDK is its emphasis on supporting a positive start in life for all children, as well as its emphasis on child poverty reduction. However, this focus on equality of opportunity and addressing disadvantage through FDK is also potentially problematic, as again, this approach does not address the structural barriers that restrict personal choice and maintain inequitable access to opportunity (Williams, 2010a). The emphasis on providing children with equal opportunities for success ultimately fails to acknowledge the systemic injustices that limit individual choice and impact people's opportunities and outcomes (Bundy, 2012). For Bundy (2012), "by concluding that investment in children offers equality of opportunity, there is the potential for further indifference to structural forces of inequality, such as class(ism), rac(ism) and (sexism)" (p. 595). Bundy (2012) further argues that "by minimising the need to solve problems that impede inequality there is a crystallisation of the discourse of individual choice leading to poverty" (p. 595). Therefore, it can be 
argued that it is important to balance an emphasis on how early childhood services can support equal opportunity and poverty reduction with acknowledging and addressing the systemic problems that render children and families vulnerable in the first place and that continue to impede well-being throughout life.

This study's CDA provided insight as to how nominalization is employed in all three of the texts included for CDA to perpetuate the principle of equality of opportunity underlying social investment discourse. Through identifying the FDK program as the Ontario government's approach to offering children a positive 'start', the texts indicate that the government is taking responsibility for children to access equal opportunity for the future. However, this approach ultimately perpetuates the emphasis that social investment places on individuals taking responsibility for their own welfare (Bundy, 2012; Cantillon \& Van Lancker, 2013). As a result, this textual process arguably works to undermine the state's responsibility for the care and well-being of all citizens.

Through understanding how the Ontario government reinforces an emphasis on individual responsibility and equal opportunity through the use of nominalization, it is possible to conceive of a different, more social justice-oriented approach to representing the program. For example, the stress placed on preparing children for the future could be balanced with equal emphasis on caring for their well-being and protecting their rights in the present, as well as acknowledging and seeking to address structural barriers that undermine the realization of equal outcomes for all children and families (Bundy, 2012; Moss, 2006; White, 2011).

Implications of Employing an Investment Rationale. Another concern that can be raised in relation to this study's findings is regarding the potential implications of 
portraying FDK as an investment in children. As the findings from this study have indicated, the Ontario government portrays the FDK program as an investment both in children and programming to support children. White (2011) argues,

The danger of resting investment arguments on research that is applicable to a very specific societal context (i.e., low income and other vulnerable groups in the United States) and extrapolating policy recommendations to other countries, is that these returns may not ultimately be realized, ultimately killing support for the programs (p. 301).

Relying on an investment-oriented rationale could jeopardize support for early childhood programming if these programs do not foster what is deemed to be a positive return.

The use of an investment rationale to justify FDK not only holds potential negative possibilities for early childhood policy, but also raises important concerns regarding social policy and citizenship in general. A fundamental problem that could follow from this investment-oriented representation of social policy is that certain social programs, and in turn citizens, may be deemed less beneficial recipients of public expenditure (Cantillon and Van Lancker, 2013). For example, children are identified as an important investment within the social investment framework "because they are seen as offering the best 'return' on investments..." (Bundy, 2012, p. 595). This approach to understanding social policy and programming can be problematic in relation to supporting social justice, as it posits "very little interest in anyone considered a bad investment or unimportant in market terms" (Bundy, 2012, p. 595). As Esping-Andersen (2002) establishes, it is important that the state's emphasis on investment is paired with a continued focus on providing citizens with social protection in order to support their basic welfare. 
A final and somewhat divergent critique of the social investment frame for expenditure on early childhood services is regarding its implications for early childhood advocacy and policy development. Harlin and Brown (2006) provide a strong critique of framing early childhood education as an investment. For Harlin and Brown (2006), the ineffectiveness of efforts to forge early childhood services as an important policy issue in the United States is linked to the portrayal these services as an intervention or investment, which does not appeal to citizens' moral, political values. Harlin and Brown (2006) argue for the importance of reframing advocacy promoting early childhood education in the United States from an investment-centered approach to a rights-based approach. Harlin and Brown (2006) state that it is important that advocacy advances an understanding of children and families' entitlement to access quality early childhood programming, which is provided by the government. For Harlin and Brown (2006), state provision of education is ultimately fundamental to supporting democracy and justice.

Benefits of a Social Pedagogical Approach. The Ontario government's social pedagogical approach to describing FDK's intended outcomes that was identified in this study offers an empowering and humanizing vision for how early childhood programming can support children's development. This rationale is set forth in certain Ontario government texts by emphasizing how FDK can support children's overall development (Please refer to Appendix C). This approach moves away from an understanding of early childhood programming as focused on simply learning and gaining skills for future employment and instead, highlights how FDK seeks to support children as entire beings (Moss, 2006; White, 2011). The social pedagogical approach seems to place responsibility on the state to not merely support children to develop the 
credentials necessary for a productive future, but also supports individuals as whole beings and citizens.

Absence of a Children's Rights Frame. While it is important to discuss the rationales that were present in the Ontario government's justification for FDK in the texts analyzed in this study, it is also valuable to briefly discuss the absence of a children's rights frame. As previously indicated, Richardson (2011) and Friendly (2006) identify this approach to framing early childhood policy which has been lacking in Canada. Despite the absence of this frame in the Ontario government's justification of FDK to the public, it is important to briefly highlight how this approach diverges from the more social investment-oriented rationales, which dominated the Ontario government's justification of FDK. This study aims to suggest the importance of including this rationale in the promotion and advocacy of future early childhood policy initiatives.

According to Woodhead (2006), "Framing early childhood policy in terms of child rights departs radically from a conventional, instrumental paradigm, notably through the insistence on every young child's entitlement to quality of life, to respect and to well being. Each entitlement is valued as an end in itself and not just as the means to achieve some distant goal of achieving potential" (p. 27). This study holds that applying a children's rights lens to the Ontario government's justification of FDK could offer an empowering representation of children as citizens in the present, who have a basic entitlement to quality care and education (Woodhead, 2006). This study further holds that a more interdiscursive representation of FDK, which combines social investment discourse with an emphasis on how FDK can protect children's rights, is necessary. 
Bridging Social Justice and Social Investment Discourse. It is important to not only explore how the Ontario government drew on social investment or social justice discourse to rationalize FDK, but also how the government employed a combination of these approaches. The representation of FDK as supporting the public education system offered a rationale that can be interpreted as supporting both discourses (Please refer to Appendix D). On the one hand, this rationale reflects a social justice-oriented focus on caring for the needs and securing the rights of children to education through protecting a publicly funded institution. However, in the Premier's Remarks at the London Chamber of Commerce (Ontario, 2013a), the importance of supporting public education was reduced to economic advancement, which arguably undermined the underlying social justice principle of this rationale. This demonstrated how the same rationale for FDK could draw on different discourses and as a result, drastically change one's understanding of the purpose of the program, as well as the Ontario government's portrayal of its overarching understanding of its responsibility to advance the welfare of citizens. Through reducing public education to achieving economic ends, the Ontario government prioritized its identity as a government that supports a competitive market. The distinction between framing public education as an end in of itself or as supporting economic progress holds important implications for how one understands the responsibilities of the state and its role in relation to supporting the welfare of citizens. Thus, the incorporation of a social justice and social investment approach within the rationale that FDK supports public education ultimately rendered completely disparate and irreconcilable representations of FDK's purpose. 
Ontario's (2013a) rationale that FDK supports public education as an end in of itself or as serving the economy seemed to place social investment and social justice in stark contrast to one another. However, the incorporation of social justice and social investment discourse in portraying how FDK supports parents living in poverty seemed to effectively combine and even reconcile these discourses in an overarching framework of support and care. On the one hand, the social investment approach emphasized that FDK can assist parents experiencing poverty by supporting their opportunity to gain further education or employment. On the other hand, the social justice approach was represented through the claim that FDK will help save parents money on childcare, which results in an immediate and universal benefit that is not attached to their employment status. Through helping reduce the costs of childcare for parents, the state is sharing some of the responsibility for the care of children with the family (Williams, 2010a). While these intended outcomes of the program are quite different, they can arguably work together to offer comprehensive support for parents experiencing poverty that not only promotes integration into the labour market but also cares for the present needs and wellbeing of families. Thus, this rationale disrupts the idea that social investment and social justice are entirely distinct or incompatible frameworks. In practice, there seems to be more interconnection between the discourses, as well as the possibility to reconcile them in a comprehensive approach to representing and justifying early childhood and family policy.

\section{Summary of Discussion}

Overall, the discussion of this study's findings from a content analysis and CDA of textual documents produced by the Ontario government has sought to shed light on the 
dominance of the social investment discourse in the Ontario government's justification for FDK and the implications this holds for this program and early childhood policy development in general. This discussion has also sought to highlight how the Ontario government's justification of FDK reflected opportunities for advancing more social justice-oriented representations of this program and even combining social investment and social justice discourses. The central purpose of discussing these findings and their implications is to encourage citizens to critically examine how particular representations of social policy and education programming are set forth by the state. The concluding chapter of this study will reflect on key insights gleaned from this study's content analysis and CDA. This chapter will also suggest recommendations for future research and will address the limitations of this study. 


\section{Chapter 8: Conclusion}

This study's analysis of political documents and speeches has shown the dominance of the social investment discourse in the Ontario government's rationalization of FDK to the public throughout these texts. Furthermore, this study has suggested that the Ontario government's use of nominalization, modality and interdiscursivity has perpetuated the social investment-oriented discursive representation of FDK within the texts. This study has raised concerns with the potential impact that the dominance of the social investment discourse in the Ontario government's representation of FDK can have in defining and potentially restricting the possibilities for early childhood policy and social welfare policy more generally.

In addition to examining the implications of key themes underlying the social investment discursive representation of FDK, this study has also sought to reveal how the Ontario government's rationalization of the FDK policy offers opportunities to envision a more socially just and caring approach to conceptualizing the benefits of early childhood policy for children and families. This is particularly demonstrated through the incorporation of a social pedagogical approach within certain texts. Furthermore, the combination of social justice and social investment discourses within particular rationales for FDK demonstrate the potential for reconciling these aims within a broader framework for conceptualizing and implementing state provision of early childhood policy.

This study's CDA of three textual documents also provided insight regarding how nominalization, modality and interdiscursivity further enhanced the dominance of social investment discourse in the Ontario government's rationalization of FDK. Through gaining insight into the textual and discursive practices that supported social investment 
discourse, the aim of this study is to encourage the adoption of a critical approach to consuming Ontario government texts and their representation of policy initiatives and to envision how alternative, more social justice-oriented representations of FDK and other early childhood policies could be set forth.

Ultimately, this study argues that applying a more social-justice oriented approach to the discursive representation of FDK can lend to early childhood policy advocacy that supports the intrinsic value of caring for and educating children (Moss, 2006; White, 2011). This study supports Williams's (2010b) claim regarding the importance of social policy discourse advancing a "political ethic of care" (p.18), whereby care is "understood as the basis of citizenship, of solidarity and of justice" (Tronto,1993; Sevenhuisjen, 1998; Williams, 2005, as cited in Williams, 2010b, p.17). Through this approach, it may be possible to both enhance productive early childhood policy but most importantly, to ensure that the state supports the well-being and rights of all children and families.

\section{Recommendations for Future Research}

Based on this study's indication of the dominance of social investment discourse in the Ontario government's justification of FDK, potential topics for future research will now be set forth. First, future research could move beyond examining how FDK is rationalized through the production of the Ontario government texts, to examining how this rationalization and the underlying discourses are consumed and influenced by the public. For example, this could involve examining how the rationalization of FDK is interpreted by key beneficiaries of the program, such as parents, through interviews. Future analysis could also explore how key stakeholders in early childhood education programming understand the central purpose of FDK. This could involve a comparison of 
how policymakers, representatives of different political parties, advocacy groups, teachers, students in FDK and the general public envision the FDK program's purpose. A final recommendation for future research examining the discursive representation of FDK or other early childhood policies is to include a similar number of texts from different genres and dates in order to facilitate an analysis of how the texts' genre and date impact the findings.

\section{Limitations}

It is necessary to acknowledge the overarching limitations of this study. First, there are limitations as a result of the methodological approach that this study adopted. As previously established, CDA has been critiqued for its lack of objectivity, as well as its reliance on the researcher's interpretation throughout the process of analyzing texts (Breeze, 2011). While the researcher has sought to clearly identify her position in relation to the research, as well as to support interpretation of the texts with previous literature, it is important to acknowledge these limitations. An additional limitation that resulted from this study's methodological approach was related to the researcher's selection of specific discursive mechanisms to examine in the texts. On the one hand, this approach strengthened this study's CDA, as it allowed for a more focused analysis of the texts. However, it is possible that a more open-ended analysis of the texts could generate a more thorough representation of the text and discourse practices that supported the perpetuation of social investment discourse in the Ontario government's justification of FDK.

While this study has limitations due to its methodological approach, another limitation is related to the use of political documents as data sources. During the 
researcher's coding and analysis, clearly identifying rationales and discourses underlying the texts' description of FDK was at times difficult due to the vagueness of certain policy documents and speeches. As the source of analysis for this study was texts, the researcher was unable to further clarify the meaning underlying certain statements in order to enhance this study's analysis of the texts, as would have been possible with a different data collection approach, such as interviewing.

A final limitation of this study is regarding the ability to generalize its findings. As the researcher only examined a select number of textual documents that reflect the Ontario government's justification of FDK to the public, the findings from this study cannot be considered representative of the entire justification process that the government set forth. Instead, this study has served as a pilot project that can inform future research seeking to establish a more extensive analysis of this topic. 


\section{Appendix A: Data Sources}

\section{Speeches from The Throne}

\begin{tabular}{|l|l|l|l|}
\hline Author & Date & Title & Retrieved From \\
\hline Ontario & $\begin{array}{l}\text { March } 8^{\text {th }}, \\
2010\end{array}$ & $\begin{array}{l}\text { "Open } \\
\text { Ontario" }\end{array}$ & $\begin{array}{l}\text { http://www.thestar.com/news/ontario/2010/ } \\
\text { 03/0xt_of_throne_speech.html }\end{array}$ \\
\hline Ontario & $\begin{array}{l}\text { November } \\
22^{\text {nd }}, 2011\end{array}$ & $\begin{array}{l}\text { "Moving } \\
\text { Ontario } \\
\text { Forward: A } \\
\text { Plan for Jobs } \\
\text { and the } \\
\text { Economy" }\end{array}$ & $\begin{array}{l}\text { http://news.ontario.ca/opo/en/2011/11/movi } \\
\text { ng-ontario-forward-a-plan-for-jobs-and-the- } \\
\text { economy.html }\end{array}$ \\
\hline Ontario & $\begin{array}{l}\text { February } \\
19^{\text {th }}, 2013\end{array}$ & $\begin{array}{l}\text { "The Way } \\
\text { Forward" }\end{array}$ & $\begin{array}{l}\text { http://news.ontario.ca/opo/en/2013/02/the- } \\
\text { way-forward-1.html }\end{array}$ \\
\hline Ontario & $\begin{array}{l}\text { July } 3^{\text {rd }}, \\
2014\end{array}$ & $\begin{array}{l}\text { "Building } \\
\text { Ontario Up" }\end{array}$ & $\begin{array}{l}\text { http://news.ontario.ca/opo/en/2014/07/buildi } \\
\text { ng-ontario-up-speech-from-the-throne.html }\end{array}$ \\
\hline
\end{tabular}

\section{Budget Speeches}

\begin{tabular}{|l|l|l|l|}
\hline Author & Date & Title & Retrieved From \\
\hline $\begin{array}{l}\text { Ontario } \\
\text { Finistry of }\end{array}$ & 2010 & $\begin{array}{l}\text { "Open } \\
\text { Ontario, } \\
\text { Ontario's } \\
\text { Plan for Jobs } \\
\text { and Growth" }\end{array}$ & $\begin{array}{l}\text { http://www.fin.gov.on.ca/en/budget/ontario } \\
\text { budgets/2010/statement.pdf }\end{array}$ \\
\hline $\begin{array}{l}\text { Ontario } \\
\text { Ministry of } \\
\text { Finance }\end{array}$ & 2011 & $\begin{array}{l}\text { "Turning the } \\
\text { Corner to a } \\
\text { Better } \\
\text { Tomorrow" }\end{array}$ & $\begin{array}{l}\text { http://www.fin.gov.on.ca/en/budget/ontario } \\
\text { budgets/2011/statement.pdf }\end{array}$ \\
\hline $\begin{array}{l}\text { Ontario } \\
\text { Ministry of } \\
\text { Finance }\end{array}$ & 2012 & $\begin{array}{l}\text { "Strong } \\
\text { Action for } \\
\text { Ontario" }\end{array}$ & http://www.fin.gov.on.ca/en/budget/ontario \\
\hline $\begin{array}{l}\text { Ontario } \\
\text { Ministry of } \\
\text { Finance }\end{array}$ & 2013 & $\begin{array}{l}\text { "A } \\
\text { Prosperous } \\
\text { and Fair } \\
\text { Ontario" }\end{array}$ & http://www.fin.gov.on.ca/en/budget/ontario \\
\hline $\begin{array}{l}\text { Ontario } \\
\text { Ministry of } \\
\text { Finance }\end{array}$ & 2014 & $\begin{array}{l}\text { "Building } \\
\text { Opportunity, } \\
\text { Securing Our }\end{array}$ & Futarement.pdf \\
\hline $\begin{array}{l}\text { Ontario } \\
\text { Ministry of } \\
\text { Finance }\end{array}$ & 2015 & $\begin{array}{l}\text { "Building } \\
\text { Ontario Up" }\end{array}$ & budgets/2014/statement.pdf \\
\hline
\end{tabular}


Additional Speeches

\begin{tabular}{|l|l|l|l|}
\hline Author & Date & Title & Retrieved From \\
\hline Ontario & $\begin{array}{l}\text { June 14, } \\
2013\end{array}$ & $\begin{array}{l}\text { Premier's } \\
\text { Remarks at } \\
\text { the London } \\
\text { Chamber of } \\
\text { Commerce }\end{array}$ & http://www.premier.gov.on.ca/en/news/263 \\
\hline Ontario & $\begin{array}{l}\text { June 24, } \\
2014\end{array}$ & $\begin{array}{l}\text { Swearing-In } \\
\text { Ceremony }\end{array}$ & $\begin{array}{l}\text { http://news.ontario.ca/opo/en/2014/06/notes } \\
\text {-for-remarks-by-kathleen-wynne-premier- } \\
\text { of-ontario-june-24-2014-swearing-in- } \\
\text { ceremony.html }\end{array}$ \\
\hline
\end{tabular}

\section{Ontario Government Progress Reports}

\begin{tabular}{|c|c|c|c|}
\hline Author & Date & Title & Retrieved From \\
\hline Ontario & 2009 & $\begin{array}{l}\text { Progress } \\
\text { Report } 2009\end{array}$ & $\frac{\text { https://dr6j45jk9xcmk.cloudfront.net/docum }}{\text { ents/73/progressreport2009en.pdf }}$ \\
\hline Ontario & 2010 & $\begin{array}{l}\text { Progress } \\
\text { Report } 2010\end{array}$ & $\begin{array}{l}\text { https://dr6j45jk9xcmk.cloudfront.net/docum } \\
\text { ents/71/progressreport2010en.pdf }\end{array}$ \\
\hline Ontario & 2011 & $\begin{array}{l}\text { Progress } \\
\text { Report } 2011\end{array}$ & $\begin{array}{l}\text { https://dr6j45jk9xcmk.cloudfront.net/docum } \\
\text { ents/75/progressreport2011en.pdf }\end{array}$ \\
\hline Ontario & 2012 & $\begin{array}{l}\text { Progress } \\
\text { Report } 2012\end{array}$ & $\begin{array}{l}\text { http://docs.files.ontario.ca/documents/142/p } \\
\text { rogressreport2012en.pdf }\end{array}$ \\
\hline Ontario & 2014 & $\begin{array}{l}\text { Progress } \\
\text { Report 2014: } \\
\text { education }\end{array}$ & $\begin{array}{l}\text { https://www.ontario.ca/government/progres } \\
\text { s-report-2014-education }\end{array}$ \\
\hline
\end{tabular}

\section{Documents Regarding Full-Day Kindergarten}

\begin{tabular}{|l|l|l|l|}
\hline Author & Date & Title & Retrieved From \\
\hline Ontario & 2010 & $\begin{array}{l}\text { Full-Day Early Learning } \\
\text { Ministry of }\end{array}$ & \\
Education & & $\begin{array}{l}\text { Kindergarten Program A } \\
\text { Reference Guide for } \\
\text { Educators for Four- and } \\
\text { Five-Year-Olds }\end{array}$ & http://www.edu.gov.on.ca/eng/curric \\
& & ulum/elementary/kinder2010.pdf \\
& & \\
\hline
\end{tabular}




\begin{tabular}{|l|l|l|l|}
\hline $\begin{array}{l}\text { Ontario } \\
\text { Ministry of }\end{array}$ & 2010 & $\begin{array}{l}\text { The Full-Day Early } \\
\text { Learning - Kindergarten } \\
\text { Program Draft Version }\end{array}$ & $\begin{array}{l}\text { http://www.edu.gov.on.ca/eng/curric } \\
\underline{\text { ulum/elementary/kindergarten_engli }} \\
\text { sh_june3.pdf }\end{array}$ \\
\hline $\begin{array}{l}\text { Ontario } \\
\text { Ministry of }\end{array}$ & 2010 & $\begin{array}{l}\text { The Full-Day Early } \\
\text { Learning- Kindergarten } \\
\text { Program The Extended } \\
\text { Day Program Draft } \\
\text { Version }\end{array}$ & $\begin{array}{l}\text { http://www.edu.gov.on.ca/eng/curric } \\
\text { ulum/elementary/kinderProgram201 } \\
\text { 0.pdf }\end{array}$ \\
\hline Ontario & 2012 & $\begin{array}{l}\text { A Question and Answer } \\
\text { Guide for Parents }\end{array}$ & $\begin{array}{l}\text { http://www.edu.gov.on.ca/kindergart } \\
\text { en/QsAsguide.pdf }\end{array}$ \\
\hline
\end{tabular}

\section{Additional Documents}

\begin{tabular}{|l|l|l|l|}
\hline Author & Date & Title & Retrieved From \\
\hline Ontario & 2014 & Realizing Our Potential: & \\
& & Ontario's Poverty & https://dr6j45jk9xcmk.cloudfront.net \\
& & Reduction Strategy, & /documents/3384/en-prs-bklt-aug- \\
& & 2014-2019 & 28th-approved-final-s.pdf \\
\hline
\end{tabular}




\section{Appendix B: Rationales Aligning with Social Investment Discourse}

\begin{tabular}{|c|c|}
\hline Rationale & Texts \\
\hline $\begin{array}{l}\text { Providing Children with Support for } \\
\text { Future Success }\end{array}$ & $\begin{array}{l}\text { - Speech from the Throne (2010) } \\
\text { - Speech from the Throne (2014) } \\
\text { - Budget Speech (2011) } \\
\text { - Budget Speech (2013) } \\
\text { - Progress Report (2010) } \\
\text { - Progress Report (2011) } \\
\text { - Progress Report (2014) } \\
\text { - Swearing in Ceremony } \\
\text { - A Question and Answer Guide for } \\
\text { Parents (2012) } \\
\text { - Full-Day Early Learning } \\
\text { Kindergarten Program A } \\
\text { Reference Guide for Educators for } \\
\text { - Four-and Five-Year-Olds }(2010) \\
\text { The Full-Day Early Learning- } \\
\text { Kindergarten Program Draft } \\
\text { Version (2010) } \\
\text { - Realizing Our Potential: Ontario's } \\
\text { Poverty Reduction Strategy, 2014- } \\
\text { 2019 (2014) }\end{array}$ \\
\hline \multicolumn{2}{|l|}{ Sub-Rationales } \\
\hline Success in Life/General & $\begin{array}{l}\text { - Speech from the Throne (2014) } \\
\text { - Progress Report (2013) } \\
\text { - Progress Report (2011) } \\
\text { - Progress Report (2014) } \\
\text { - A Question and Answer Guide for } \\
\text { Parents (2012) } \\
\text { - Full-Day Early Learning } \\
\text { Kindergarten Program A } \\
\text { Reference Guide for Educators for } \\
\text { Four-and Five-Year-Olds }(2010) \\
\text { - The Full-Day Early Learning- } \\
\text { Kindergarten Program Draft } \\
\text { Version (2010) } \\
\text { - Realizing Our Potential: Ontario's } \\
\text { Poverty Reduction Strategy, 2014- } \\
\text { 2019 (2014) }\end{array}$ \\
\hline Success in Learning and Development & $\begin{array}{l}\text { - A Question and Answer Guide for } \\
\text { Parents (2012) }\end{array}$ \\
\hline
\end{tabular}




\begin{tabular}{|c|c|}
\hline & $\begin{array}{l}\text { - Full-Day Early Learning } \\
\text { Kindergarten Program A } \\
\text { Reference Guide for Educators for } \\
\text { Four-and Five-Year-Olds (2010) } \\
\text { - The Full-Day Early Learning- } \\
\text { Kindergarten Program Draft } \\
\text { Version (2010) } \\
\end{array}$ \\
\hline Success in Formal Education and Training & $\begin{array}{l}\text { - Speech from the Throne (2010) } \\
\text { - Budget Speech (2011) } \\
\text { - Swearing-In Ceremony (2014) } \\
\text { - Progress Report (2010) } \\
\text { - Progress Report (2011) } \\
\text { - A Question and Answer Guide for } \\
\text { Parents (2012) } \\
\text { - Full-Day Early Learning } \\
\text { Kindergarten Program A } \\
\text { Reference Guide for Educators for } \\
\text { - Four-and Five-Year-Olds (2010) } \\
\text { The Full-Day Early Learning- } \\
\text { Kindergarten Program Draft } \\
\text { Version (2010) }\end{array}$ \\
\hline Success in Obtaining a Job & $\begin{array}{l}\text { - Speech from the Throne (2010) } \\
\text { - Budget Speech (2011) } \\
\text { - Progress Report (2010) }\end{array}$ \\
\hline $\begin{array}{l}\text { Success in Obtaining a Good Standard of } \\
\text { Living }\end{array}$ & - Budget Speech (2011) \\
\hline Success in Contributing to ON/Society & $\begin{array}{ll}\text { - } & \text { Budget Speech (2011) } \\
\text { - } & \text { Full-Day Early Learning } \\
& \text { Kindergarten Program A } \\
& \text { Reference Guide for Educators for } \\
& \text { Four-and Five-Year-Olds (2010) }\end{array}$ \\
\hline
\end{tabular}

\begin{tabular}{|l|l|}
\hline \multicolumn{1}{|c|}{ Rationale } & \multicolumn{1}{c|}{ Texts } \\
\hline Building a Stronger Economy & - Speech from the Throne (2010) \\
& - Budget Speech (2015) \\
& - A Question and Answer Guide for \\
& Parents (2012) \\
& Full-Day Early Learning \\
& Kindergarten Program A \\
& Reference Guide for Educators for \\
& Four-and Five-Year-Olds (2010) \\
\hline
\end{tabular}




\begin{tabular}{|c|c|}
\hline Rationale & Texts \\
\hline Building a Stronger Workforce & 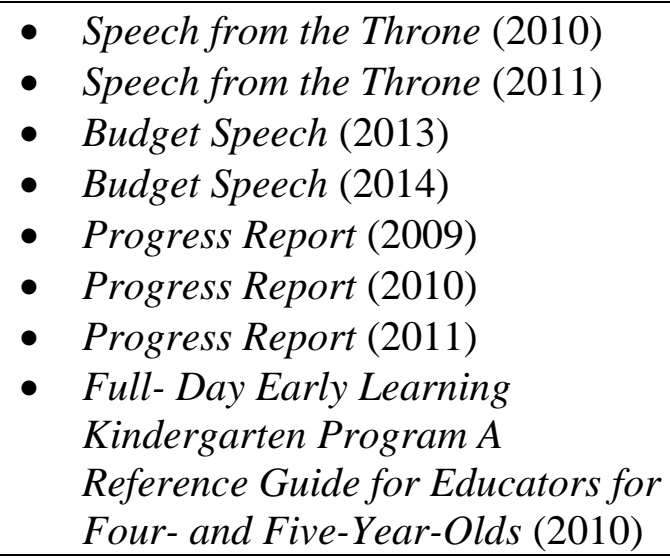 \\
\hline
\end{tabular}

\begin{tabular}{|l|l|}
\hline \multicolumn{1}{|c|}{ Rationale } & \multicolumn{1}{c|}{ Texts } \\
\hline Supporting Working Parents & - Speech from the Throne (2010) \\
& - Budget Speech (2011) \\
& - Progress Report (2010) \\
& - Progress Report (2011) \\
\hline
\end{tabular}

\begin{tabular}{|l|l|}
\hline \multicolumn{1}{|c|}{ Rationale } & \multicolumn{1}{c|}{ Texts } \\
\hline Supporting Children Experiencing & - Speech from the Throne (2010) \\
Poverty & - Progress Report (2010) \\
& - Progress Report (2011) \\
& - Realizing Our Potential: Ontario's \\
& Poverty Reduction Strategy, 2014- \\
& 2019 (2014) \\
\hline
\end{tabular}

\begin{tabular}{|l|l|}
\hline \multicolumn{1}{|c|}{ Rationale } & \multicolumn{1}{c|}{ Texts } \\
\hline Investing in Children and Educational & - Budget Speech (2013) \\
Programming & - Budget Speech (2015) \\
& - Progress Report (2011) \\
& - Premier's Remarks at the London \\
& Chamber of Commerce (2013) \\
\hline
\end{tabular}

\begin{tabular}{|l|c|}
\hline \multicolumn{1}{|c|}{ Rationale } & Texts \\
\hline Supporting Future Generations & $\bullet \quad$ Progress Report (2014) \\
\hline
\end{tabular}




\section{Appendix C: Rationales Aligning with Social Justice Discourse}

\begin{tabular}{|l|l|}
\hline \multicolumn{1}{|c|}{ Rationale } & Texts \\
\hline Supporting All Parents and Families & ・ Budget Speech (2011) \\
& • Progress Report (2011) \\
& - Progress Report (2014) \\
\hline
\end{tabular}

\begin{tabular}{|c|c|}
\hline Rationale & Texts \\
\hline $\begin{array}{l}\text { Supporting Children's Present Well- } \\
\text { Being }\end{array}$ & $\begin{array}{l}\text { - Full- Day Early Learning } \\
\text { Kindergarten Program A } \\
\text { Reference Guide for Educators for } \\
\text { Four-and Five-Year-Olds (2010) } \\
\text { - The Full-Day Early Learning- } \\
\text { Kindergarten Program Draft } \\
\text { Version (2010) } \\
\text { - The Full-Day Early Learning- } \\
\text { Kindergarten Program The } \\
\text { Extended Day Program Draft } \\
\text { Version (2010) }\end{array}$ \\
\hline
\end{tabular}

\begin{tabular}{|l|ll|}
\hline \multicolumn{1}{|c|}{ Rationale } & \multicolumn{1}{c|}{ Texts } \\
\hline Supporting Children's Holistic & - & Full-Day Early Learning \\
Development & Kindergarten Program A \\
& Reference Guide for Educators for \\
& Four-and Five-Year-Olds (2010) \\
& - The Full-Day Early Learning- \\
& Kindergarten Program Draft \\
& Version (2010) \\
& - Progress Report (2011) \\
& - Realizing Our Potential: Ontario's \\
& Poverty Reduction Strategy, 2014- \\
& 2019 (2014) \\
\hline
\end{tabular}




\section{Appendix D: Rationales Aligning with Social Justice and Social Investment Discourse}

\begin{tabular}{|c|c|}
\hline \multicolumn{1}{|c|}{ Rationale } & \multicolumn{1}{c|}{ Texts } \\
\hline Supporting Parents Experiencing Poverty & $\bullet \begin{array}{l}\text { Realizing Our Potential: } \text { Ontario's } \\
\text { Poverty Reduction Strategy, 2014- } \\
2019(2014)\end{array}$ \\
\hline
\end{tabular}

\begin{tabular}{|c|c|}
\hline Rationale & Texts \\
\hline Supporting the Public Education System & $\begin{array}{l}\text { - Realizing Our Potential: Ontario's } \\
\text { Poverty Reduction Strategy, 2014- } \\
2019 \text { (2014) } \\
\text { - Premier's Remarks at the London } \\
\text { Chamber of Commerce (2013) } \\
\text { - A Question and Answer Guide for } \\
\text { Parents (2012) } \\
\text { - Speech from the Throne (2013) } \\
\text { - Full- Day Early Learning } \\
\text { Kindergarten Program A } \\
\text { Reference Guide for Educators for } \\
\text { Four-and Five-Year-Olds (2010) }\end{array}$ \\
\hline
\end{tabular}


Appendix E: Figures Demonstrating Frequency of Social Investment, Social Justice and a Combination of the Two Discourses

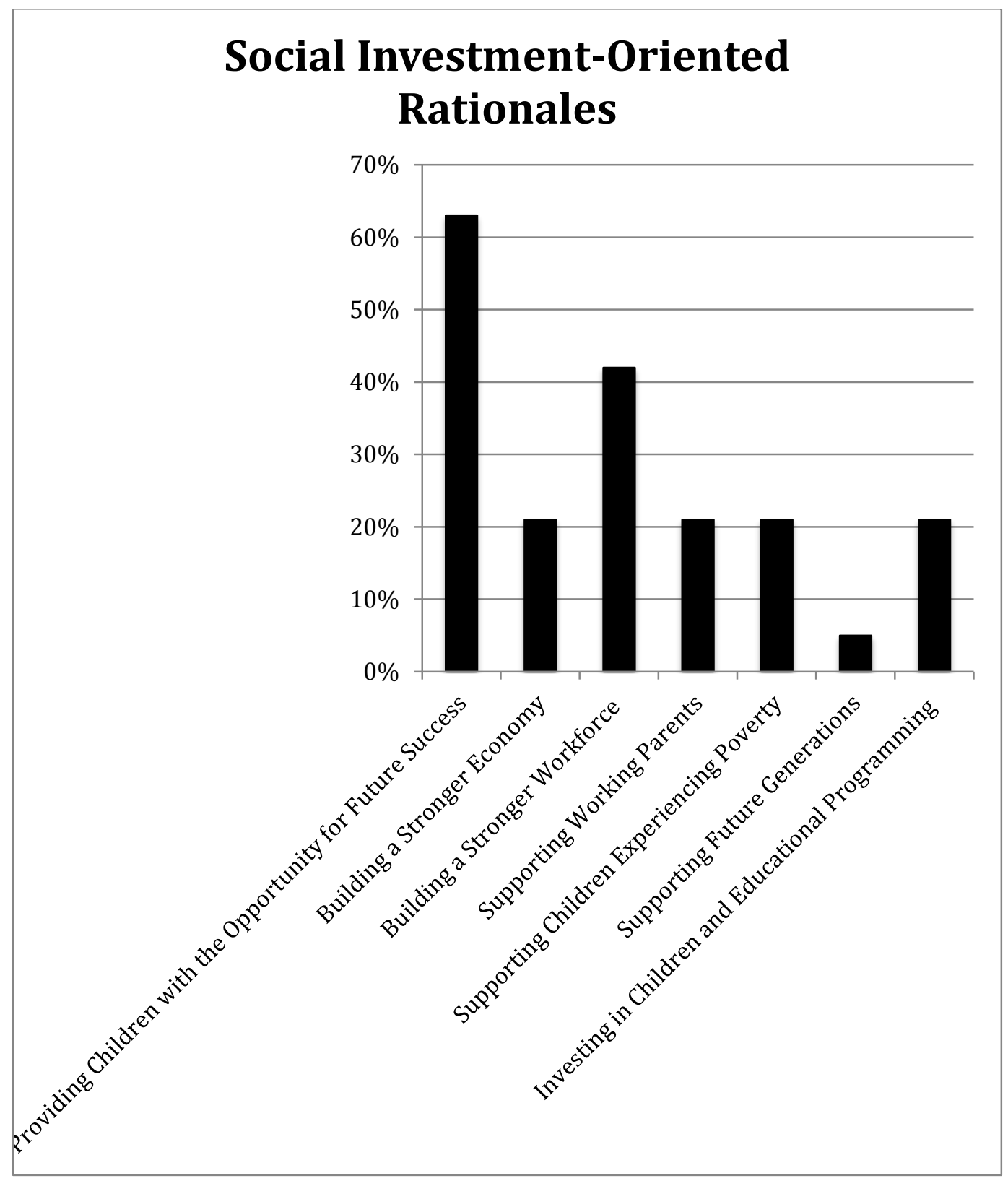

(Figure 1: This figure portrays the percentage of 19 texts that present a rationale that reflects Social Investment discourse). 


\section{Social Justice-Oriented Rationales}

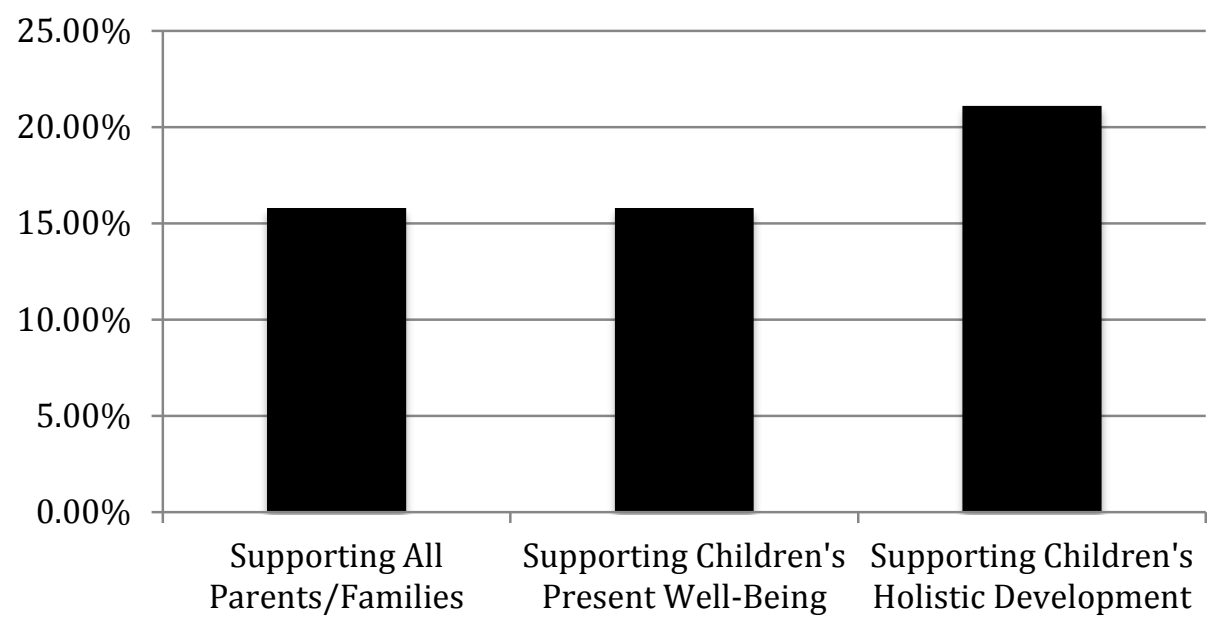

(Figure 2: This figure portrays the percentage of 19 texts that present a rationale that reflects Social Justice discourse).

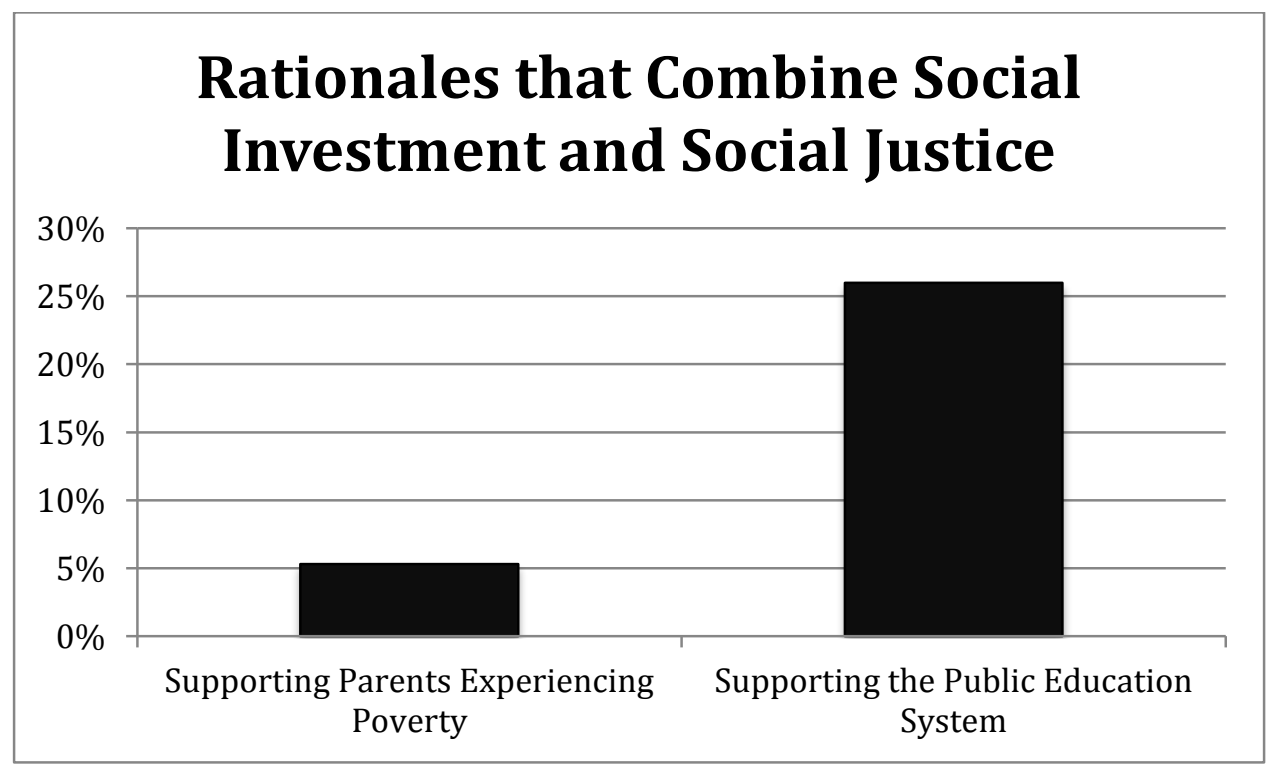

(Figure 3: This figure portrays the percentage of 19 texts that present a rationale that reflects both Social Investment and Social Justice discourse). 


\section{Appendix F: Frequency of Discourses According to Genre}

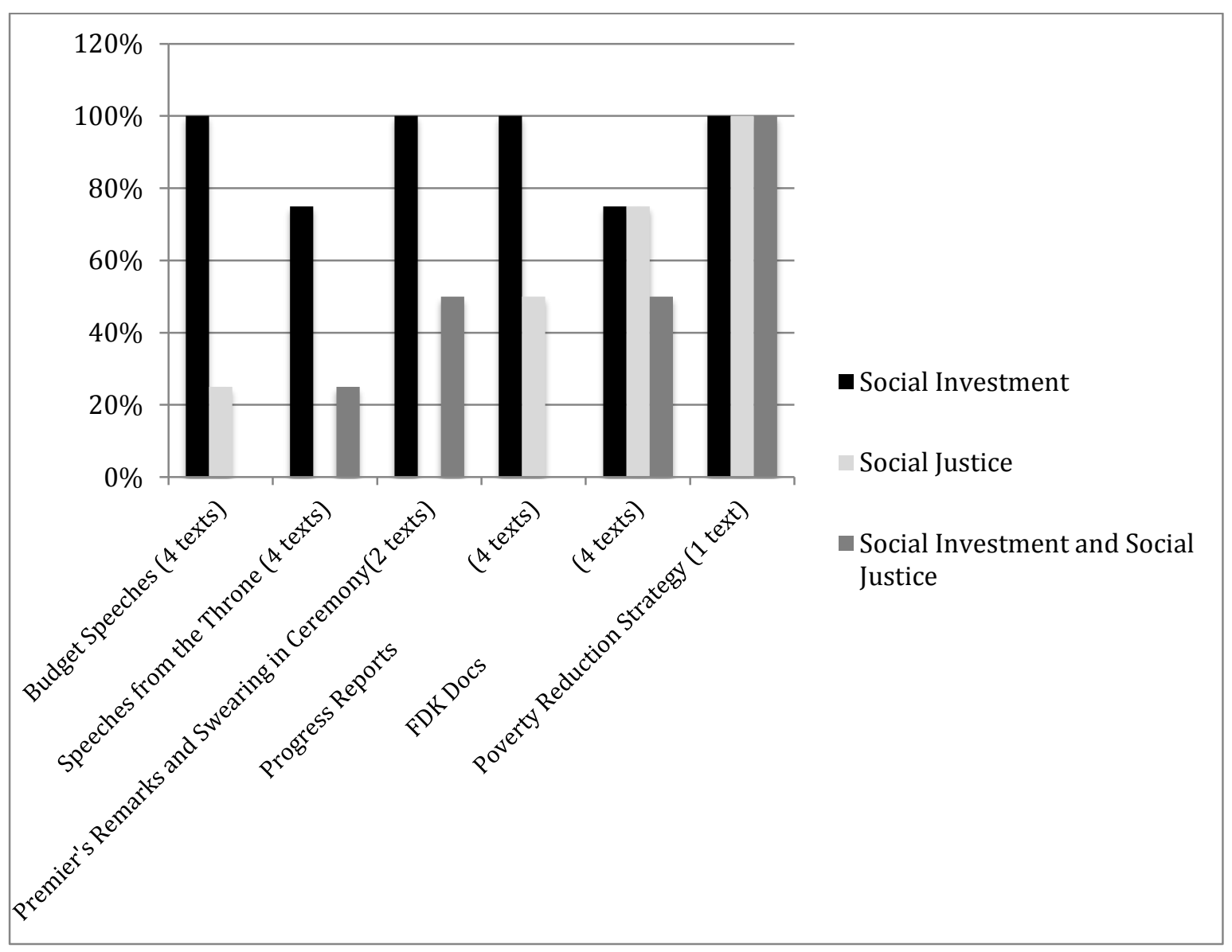


Appendix G: Frequency of Discourses According to Date

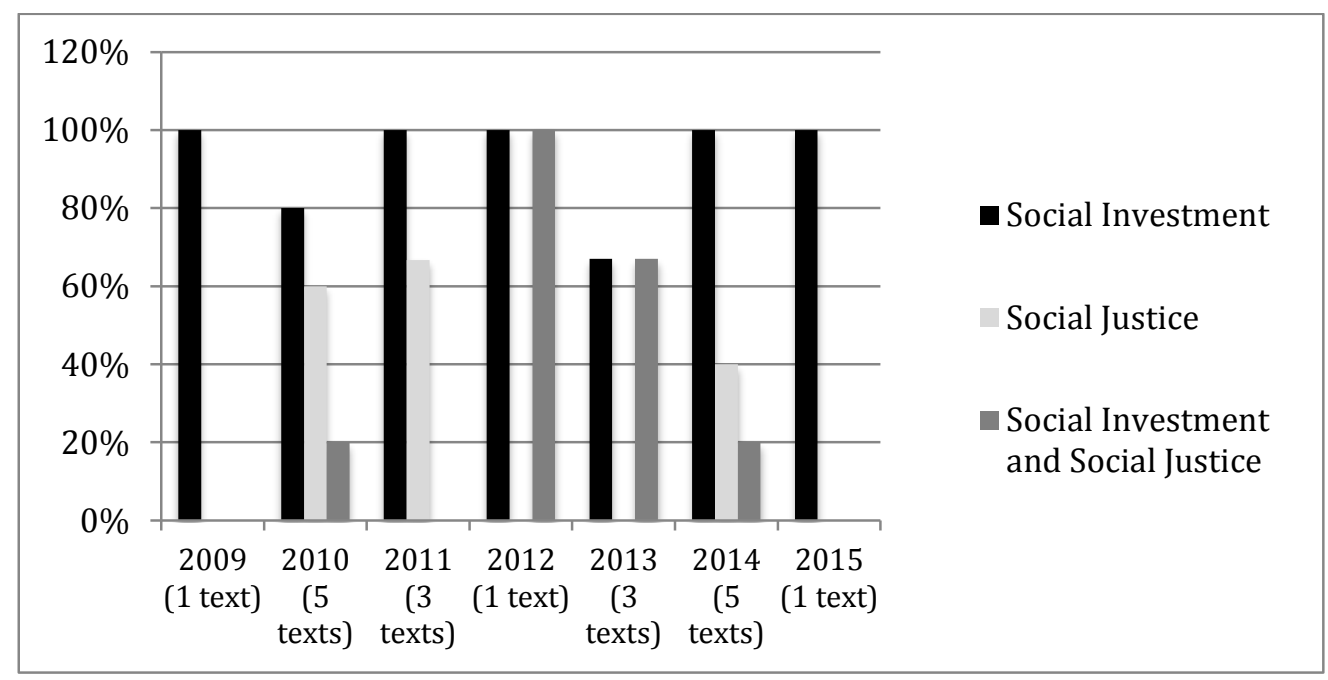




\section{Appendix H: Texts Used for CDA}

\section{Text from Open Ontario (Ontario, 2010a)}

"Ontarians are some of the most highly skilled and educated workers in the world. And that gives us a competitive edge.

It is an edge we must sharpen even further.

That's why, starting this fall, full-day learning for four- and five-year-olds will begin at schools across our province.

This is the first program of its kind in North America.

It's part of a plan to help more children get a strong start in school -- so they can go on to college, university or training programs -- and find a great job.

It will help lift more children out of poverty.

It will help busy parents balance their work and their family lives.

It will build a stronger economy for Ontario.

Because to put it simply -- the places with the strongest schools, today, will have the strongest economies tomorrow" (Ontario, 2010a, p. 6-7).

\section{Text from A Question and Answer Guide for Parents (Ontario, 2012a)}

"Why has Ontario introduced full-day kindergarten?

In today's complex world, education is more important than ever for our children. Full-day kindergarten is designed to give your child a stronger start in school and in life. Full-day kindergarten for four- and five-year-olds is part of Ontario's plan to support early learning and child development, build a stronger school system and contribute to Ontario's long-term economic competitive advantage" (Ontario, 2012a, p. 1). 


\section{Text from Poverty Reduction Strategy (Ontario, 2014c)}

"Full-Day Kindergarten and Early Learning: A strong start

Full-day kindergarten is one of the most significant improvements made to Ontario's education system in decades. The program is giving children a stronger start in life through early learning programs. For any child of any background, high-quality early learning can help to identify learning needs at an earlier stage, so they can get the additional support they need to succeed. Early learning also gives us a jump on closing achievement gaps. Our approach to kindergarten offers children a full day of learning that will help them develop the social, emotional, academic and physical skills that provide a good foundation for success in school and in life. By the time children from lowincome families start school, they may already face disadvantages compared to their peers from higher-income families. Enriched education environments, such as the one provided by full-day kindergarten, can help to close that gap. Full-day kindergarten also helps parents living in poverty by providing more time in the day to pursue education, training or employment while reducing child care costs by approximately $\$ 6,500$ per year" (Ontario, 2014c, p. 19). 


\section{References}

Adamson, E., Brennan, D. (2014). Social investment or Private Profit? Diverging Notions of 'Investment' in Early Childhood Education and Care. International Journal of Early Childhood,46(1), pp. 47-61. doi:10.1007/s13158-013-0098-х

Bae, B. (2010). Realizing children's right to participation in early childhood settings: Some critical issues in a Norwegian context. Early Years, 30(3), pp. 205-218. doi:10.1080/09575146.2010.506598

Bonoli, G. (2005). The politics of the new social policies. Providing coverage against new social risks in mature welfare states. Policy and Politics,33 (3), pp. 431-49, Retrieved from, http://docserver.ingentaconnect.com/deliver/connect/tpp/03055736/v33n3/s4.pdf? expires $=1437605828 \& \mathrm{id}=82340262 \&$ titleid $=777 \&$ accname $=$ Ryerson + University +Library\&checksum=437786A050D980304589A723A6C94883

Bowen, G.A. (2009). Document Analysis as a Qualitative Research Method. Qualitative Research Journal, 9(2), pp. 27-49, Retrieved from file:///Users/owner1/Downloads/Document_analysis_as_a_qualita.PDF

Breeze, R. (2011). Critical discourse analysis and its critics. Pragmatics: Quarterly Publication of the International Pragmatics Association 21(4), pp. 493525. doi:10.1075/prag.21.4.01bre

Bundy, J. (2012). Rendering (gender) invisible: Early childhood education and care in Ontario as a biopolitical social investment apparatus. Discourse: Studies in the Cultural Politics of Education, 33(4), pp. 591-605. doi: $10.1080 / 01596306.2012 .692964$ 
Cantalini-Williams, M., Telfer, L. (2010). Successful Implementation of the Full-Day Early Learning- Kindergarten Program. Principal Connections, 14(1), p. 4-7, Retrieved from http://eyeonkids.ca/docs/files/canatliniwilliams_full_day_leadership\%5B1\%5D.pdf

Cantillon, B., Van Lancker, W. (2013). Three Shortcomings of the Social investment Perspective. Social Policy \& Society, 12(4), pp. 553-564. doi:10.1017/S1474746413000080

Cockburn, T. (2005). Children and the Feminist Ethic of Care, SAGE Publications, 12(1), 71-8, Retrieved from http://chd.sagepub.com/content/12/1/71.full.pdf+html

Colechin, J.L. (2010). Expansion Despite Permanent Austerity? Innovative Aspects of Social Policy in Liberal Welfare Regimes (Unpublished doctoral dissertation). The University of Birmingham, Birmingham, UK.

Creswell, J. (2014). Research design: Qualitative, quantitative, and mixed method approaches. (4th ed.). Thousand Oaks, CA: Sage Publications.

Dobrowolsky, A., Saint-Martin, D. (2005). Agency, actors and change in a childfocused future: 'path dependency' problematised. Commonwealth \& Comparative Politics, 43(1), pp.1-33. doi:10.1080/14662040500054198

Elo, S., Kyngäs H. (2008). The qualitative content analysis process. Journal of Advanced Nursing, 62(1): pp. 107-115. Doi://10/1111/j.1365-2648.2007.04569.x

Esping-Andersen, G. (2002). A Child-Centered Social investment Strategy. In G. EspingAndersen, D. Gaille, A. Hemerjick, J. Myles (Eds.) Why We Need a New Welfare 
State. Oxford University Press.

Fairclough, N. (1995). Media Discourse. New York: E. Arnold.

Fairclough, N. (2000). New labour, new language? London, UK: Routledge.

Fairclough, N. (2003). Analyzing Discourse: Textual analysis for social research. London, UK: Routledge.

Fairclough, N. (2010). Critical Discourse Analysis. The Critical Study of Language. $\left(2^{\text {nd }}\right.$ Ed.) Harlow, UK: Pearson Education Limited.

Friendly, M. (2006). Canadian early learning and child care and the Convention on the Rights of the Child. Toronto, Ontario: Childcare Resource and Research Unit, University of Toronto.

Friendly, M., Doherty, G., Beach, J. (2006). Quality by Design: What Do We Know About Quality In Early Learning and Child Care, and What Do We Think? A Literature Review. Toronto Canada: Childcare Resource and Research Unit, University of Toronto.

Friendly, M. (2008). Building a Strong and Equal Partnership between Childcare and Early Childhood Education in Canada. International Journal of Child Care and Education Policy, 2(1), 39-52, Retrieved from http://leadershiplinc.illinoisstate.edu/downloads/pk-3incanada.pdf

Gananathan, R. (2011). Implications of Full Day Kindergarten Program Policy on Early Childhood Pedagogy and Practice. International Journal of Child Care and Education Policy, 5(2), pp. 33-45. doi:10.1007/2288-6729-5-2-33

Giddens, A. (1998). Third Way: The Renewal of Social Democracy. Cambridge, UK: Polity. 
Hajer, M. A. (1993). Discourse Coalitions and the Institutionalization of Practice: The Case of Acid Rain in Britain. In F. Fischer \& J, Forester (Eds.), The Argumentative Turn in Policy Analysis and Planning (pp. 43-76). Durham, NC: Duke University Press.

Hall, P. A. (1992). The Movement from Keynesianism to Monetarism: Institutional Analysis and British Economic Policy in the 1970s. In S. Steinmo, K. Thelen, F. Longstreth (Eds.), Structuring Politics: Historical Institutionalism in Comparative Analysis, (pp.90-113). New York, NY: Cambridge University Press.

Harlin, R., Brown, C. (2006). Issues in Education: A Universal Early Childhood Education System. Childhood Education, 83(1), pp.44-47. DOI: $1080 / 0094056.2006 .10522876$

Heckman, J.J. (2011). The Economics of Inequality The Value of Early Childhood Education. American Educator,35(1), pp. 31-47, Retrieved from http://files.eric.ed.gov/fulltext/EJ920516.pdf

Held, V. (2005). The Ethics of Care as Moral Theory. The Ethics of Care: Personal, Political, and Global. Oxford, UK: University of Oxford Press.

Hemerijck, A. (2011). The social investment imperative beyond the financial crisis. European Policy Centre, 21, pp. 11-19, Retrieved from, http://www.epc.eu/documents/uploads/pub_1281_challenge21.pdf

Herczog, M. (2012). Rights of the Child and Early Childhood Education and Care in Europe. European Journal of Education, 47(4), pp. 542-555. 
doi:10.1111/ejed.12008

Hsieh, H., \& Shannon, S. E. (2005). Three approaches to qualitative content analysis. Qualitative Health Research, 15(9), pp.1277-1288. doi: $10.1177 / 1049732305276687$

Jenson, J., Saint-Martin, D. (2003). New Routes to Social Cohesion? Citizenship and the Social investment State. The Canadian Journal of Sociology, 28(1), pp. 77-99, Retrieved from http://www.jstor.org/stable/3341876

Lakoff, G. (2014). The All New Don't Think of an Elephant! Know Your Values and Frame the Debate. White River Junction, VT: Chelsea Green Publishing.

Langford, R., Prentice, S., Albanese, P., Summers, B., Messina-Goertzen, B., \& Richardson, B. (2013). Professionalization as an advocacy strategy: A content analysis of Canadian child care social movement organizations' 2008 discursive resources. Early Years, 33(3), pp. 302-217. http://dx.doi.org/10.1080/09575146.2013.789489

Mahon, R. (2008). Varieties of liberalism: Canadian social policy from the 'Golden Age' to the present. Social Policy \& Administration, 42(4), 342-361.

DOI: $10.1111 / \mathrm{j} .1467-9515.2008 .00608 . x$

Mahon, R. (2010). After neo-liberalism? The OECD, the World Bank and the Child. Global Social Policy, 10(2), pp. 172-192. doi:10.1177/1468018110366615

McCain, M.N., Mustard, J.F. (1999). Reversing the real brain drain: Early years study. Toronto, Ontario: The Canadian Institute for Advanced Research. 
Morel, N., Palier, B., Palme, J. (2012). Beyond the welfare state as we know it? In N. Morel, B. Palier \& J. Palme (Eds.), Towards a Social investment Welfare State? Ideas, Policies and Challenges (pp. 1-30). Bristol, UK: The Policy Press.

Morgan, K. (2009). Child Care and the Social investment Model: Political Conditions for Reform. In N. Morel, B. Palier, \& J. Palme (Eds.), What Future for Social Investment? (pp. 45- 53). Stockholm Sweden: Institute for Futures Studies. Moss, P. (2006). From a Childcare to a Pedagogical Discourse- or Putting Care in Its Place. In J. Lewis (Eds.), Children, Changing Families and Welfare States. (pp. 154-172). Cheltenham, UK: Edward Elgar.

Moss, P. (2007). Bring politics into the nursery: early childhood education as a democratic practice. European Early Childhood Education Research Journal, 15(1), pp. 5-20. http://dx.doi.org/10/1080/13502930601046620

Nikolai, R. (2009). Towards Social investment? Patterns of Public Policy in the OECD World. . In N. Morel, B. Palier, \& J. Palme (Eds.), What Future for Social Investment? (pp. 99-115) Stockholm: Institute for Futures Studies.

Nolan, B. (2013). What use is 'social investment'? Journal of European Social Policy, 23(5), pp. 459-468, DOI: 10.1177/0958928713499177

Ontario. (2009). Progress Report 2009. Retrieved from, https://dr6j45jk9xcmk.cloudfront.net/documents/73/progressreport2009en.pdf Ontario. (2010a). Open Ontario. Retrieved from, http://www.thestar.com/news/ontario/2010/03/08/text_of_throne_speech.html Ontario. (2010b). Progress Report 2010. Retrieved from, https://dr6j45jk9xcmk.cloudfront.net/documents/71/progressreport2010en.pdf 
Ontario. (2011a). Moving Ontario Forward: A Plan for Jobs and the Economy.

Retrieved from,

http://news.ontario.ca/opo/en/2011/11/moving-ontario-forward-a-plan-for-jobsand-the-economy.html

Ontario. (2011b). Progress Report 2011. Retrieved from, https://dr6j45jk9xcmk.cloudfront.net/documents/75/progressreport2011en.pdf

Ontario. (2012a). A Question and Answer Guide for Parents. Retrieved from, http://www.edu.gov.on.ca/kindergarten/QsAsguide.pdf

Ontario. (2012b). Progress Report 2012. Retrieved from, http://docs.files.ontario.ca/documents/142/progressreport2012en.pdf

Ontario. (2013a). Premier's Remarks at the London Chamber of Commerce. Retrieved from, http://www.premier.gov.on.ca/en/news/26359

Ontario. (2013b). The Way Forward. Retrieved from, http://news.ontario.ca/opo/en/2013/02/the-way-forward-1.html

Ontario. (2014a). Building Ontario Up. Retrieved from, http://news.ontario.ca/opo/en/2014/07/building-ontario-up-speech-from-thethrone.html

Ontario. (2014b). Progress Report 2014: education. Retrieved from, https://www.ontario.ca/government/progress-report-2014-education

Ontario. (2014c). Realizing Our Potential: Ontario’s Poverty Reduction Strategy, 20142019. Retrieved from, 
https://dr6j45jk9xcmk.cloudfront.net/documents/3384/en-prs-bklt-aug-28thapproved-final-s.pdf

Ontario. (2014d). Swearing-In Ceremony. Retrieved from, http://news.ontario.ca/opo/en/2014/06/notes-for-remarks-by-kathleen-wynnepremier-of-ontario-june-24-2014-swearing-in-ceremony.html

Ontario Ministry of Education. (2010a). The Full-Day Early Learning-Kindergarten Program (Draft Version). Retrieved from http://www.edu.gov.on.ca/eng/curriculum/elementary/kindergarten_english_june3 .pdf

Ontario Ministry of Education. (2010b). The Full-Day Early Learning- Kindergarten Program The Extended Day Program Draft Version. Retrieved from, http://www.edu.gov.on.ca/eng/curriculum/elementary/kinderProgram2010.pdf

Ontario Ministry of Education. (2010c). Full- Day Early Learning Kindergarten Program A Reference Guide for Educators for Four- and Five-Year-Olds. Retrieved from, http://www.edu.gov.on.ca/eng/curriculum/elementary/kinder2010.pdf

Ontario Ministry of Finance. (2010). Open Ontario, Ontario's Plan for Jobs and Growth. Retrieved from, http://www.fin.gov.on.ca/en/budget/ontariobudgets/2010/statement.pdf

Ontario Ministry of Finance. (2011). Turning the Corner to a Better Tomorrow. Retrieved from, http://www.fin.gov.on.ca/en/budget/ontariobudgets/2011/statement.pdf

Ontario Ministry of Finance. (2012). Strong Action for Ontario. Retrieved from, http://www.fin.gov.on.ca/en/budget/ontariobudgets/2012/statement.pdf 
Ontario Ministry of Finance. (2013) A Prosperous and Fair Ontario. Retrieved from, http://www.fin.gov.on.ca/en/budget/ontariobudgets/2013/statement.pdf

Ontario Ministry of Finance. (2014). Building Opportunity, Securing Our Future. Retrieved from, http://www.fin.gov.on.ca/en/budget/ontariobudgets/2014/statement.pdf

Ontario Ministry of Finance. (2015). Building Ontario Up. Retrieved from, http://www.fin.gov.on.ca/en/budget/ontariobudgets/2015/statement.pdf

Pascal, C. E., \& Ontario. (2009). With our best future in mind: Implementing early learning in Ontario : report to the Premier by the special advisor on Early Learning. Toronto: Govt. of Ontario.

Pelletier, J. (2013). Ontario’s Full-Day Kindergarten: A Bold Public Policy Initiative. Public Sector Digest. Retrieved from http://www.oise.utoronto.ca/atkinson/UserFiles/File/Publications/6-2014__Ontario_s_Full-day_Kindergarten_A_Bold_Public_Policy_Initiative.pdf

Prentice, S. (2009). High Stakes: The 'Investable' Child and the Economic Reframing of Childcare. Signs, 34(3), pp. 687-710. DOI: 10.1086/593711

Richardson, B. (2011). A matter of choice: A critical discourse analysis of ECEC policy in Canada's 2006 federal election. Childcare Resource and Research Unit, Retrieved from http://www.childcarecanada.org/sites/default/files/OccasionalPaper25.pdf 
Richardson, B. \& Langford, R. (2014). A shifting collective identity: A critical discourse analysis of the Child Care Advocacy Association of Canada's public messaging in 2005 and 2008. Critical Discourse Studies, 12(1), pp. 78-96. http://dx.doi.org/10.1080/17405904.2014.962068

Tesch, R.(1990). Qualitative research: Analysis Types and Software Tools. Philadelphia, PA: Falmer.

Tronto, J. (2013). Caring democracy: Markets, Equality and Justice. New York: New York University Press

Turgeon, L. (2014). Activists, policy sedimentation, and policy change: The case of early childhood education in Ontario. Journal of Canadian Studies, 48(2), pp. 224-249. DOI: $10.1353 /$ jcs.2014.0026

Van Lancker, W. (2013). Putting the child-centred investment strategy to the test: Evidence for the EU27. Working Paper No. 13, pp. 1-27, Retrieved from http://www.centrumvoorsociaalbeleid.be/sites/default/files/CSB\%20Working\%20 Paper\%2013\%2001_January\%202013.pdf

White, L. A. (2011). The Internationalization of Early Childhood Education and Care Issues: Framing Gender Justice and Child Well Being. Governance: An International Journal of Policy, Administration, and Institutions, 24(2), pp. 285309, Retrieved from, http://journals1.scholarsportal.info.ezproxy.lib.ryerson.ca/pdf/09521895/v24i0002 /285_tioecefgjacw.xml

White, L. A. (2012). Must we all be paradigmatic? Social investment policies and liberal welfare states. Canadian Journal of Political Science, 45(3), pp. 657-683. 
doi:10.1017/S0008423912000753

Williams. F. (2010a) Claiming and Framing in the Making of Care Policies: The Recognition and Redistribution of Care United Nations Research Institute for Social Development. Gender and Development Programme Paper Number 13. Retrieved from http://www.unrisd.org/80256B3C005BCCF9/\%28httpAuxPages\%29/F0924AD81 7FE8620C125780F004E9BCD/\$file/Williams.pdf

Williams, F. (2010, July 11b). Claiming and Framing in the Making of Care Policies: The Recognition and Redistribution of Care. Paper presented at International Carers Conference: New Frontiers in Caring: 2010 and Beyond. Retrieved from, http://www.sociology.leeds.ac.uk/assets/files/research/circle/fifthcarersconference /fiona-williams-claiming-framing-making-care-policies.pdf

Woodhead, M. (2006). Changing perspectives on early childhood: theory, research and policy. Education for All Global Monitoring Report 2007, Strong foundations: early childhood care and education. Retrieved from, http://unesdoc.unesco.org/images/0014/001474/147499e.pdf 